\title{
The CUL4-DDB1 ubiquitin ligase complex controls adult and embryonic stem cell differentiation and homeostasis
}

\begin{abstract}
Jie Gao ${ }^{1,2 \dagger}$, Shannon M Buckley 1,2,3†, Luisa Cimmino ${ }^{1,2}$, Maria Guillamot ${ }^{1,2}$, Alexandros Strikoudis ${ }^{1,2}$, Yong Cang ${ }^{4}$, Stephen P Goff ${ }^{5}$, lannis Aifantis ${ }^{1,2 *}$
\end{abstract}

${ }^{1}$ Department of Pathology, New York University School of Medicine, New York, United States; ${ }^{2}$ Perlmutter Cancer Center, New York University School of Medicine, New York, United States; ${ }^{3}$ Department of Genetics, Cell Biology, and Anatomy, University of Nebraska Medical Center, Omaha, United States; ${ }^{4}$ Signal Transduction Program, Sanford-Burnham Medical Research Institute, La Jolla, United States; ${ }^{5}$ Department of Biochemistry and Molecular Biophysics, Howard Hughes Medical Institute, Columbia University, New York, United States

Abstract Little is known on post-transcriptional regulation of adult and embryonic stem cell maintenance and differentiation. Here we characterize the role of Ddb1, a component of the CUL4DDB1 ubiquitin ligase complex. Ddb1 is highly expressed in multipotent hematopoietic progenitors and its deletion leads to abrogation of both adult and fetal hematopoiesis, targeting specifically transiently amplifying progenitor subsets. However, Ddb1 deletion in non-dividing lymphocytes has no discernible phenotypes. Ddb1 silencing activates Trp53 pathway and leads to significant effects on cell cycle progression and rapid apoptosis. The abrogation of hematopoietic progenitor cells can be partially rescued by simultaneous deletion of Trp53. Conversely, depletion of DDB1 in embryonic stem cell (ESC) leads to differentiation albeit negative effects on cell cycle and apoptosis. Mass spectrometry reveals differing protein interactions between DDB1 and distinct DCAFs, the substrate recognizing components of the E3 complex, between cell types. Our studies identify CUL4-DDB1 complex as a novel post-translational regulator of stem and progenitor maintenance and differentiation.

DOI: 10.7554/eLife.07539.001
*For correspondence: iannis. aifantis@nyumc.org

${ }^{\dagger}$ These authors contributed equally to this work

Competing interest: See page 18

Funding: See page 18

Received: 17 March 2015

Accepted: 26 November 2015

Published: 27 November 2015

Reviewing editor: Amy J Wagers, Harvard University, United States

(c) Copyright Gao et al. This article is distributed under the terms of the Creative Commons Attribution License, which permits unrestricted use and redistribution provided that the original author and source are credited.

\section{Introduction}

Stem cells posses the unique properties of self-renewal and the capacity to differentiate to multiple cell types. In the case of hematopoietic stem cells (HSC) they are rare and specialized cells, which are able to give rise to all blood lineages. The balance between HSC self-renewal and differentiation needs to be tightly regulated in order to keep the HSC pool size as well as to constantly replenish mature blood cells (Orkin and Zon, 2008). HSC function is governed extrinsically by cytokines (Zsebo et alı, 1990; de Sauvage et al., 1996) and developmental signals (Stier et alo, 2002; Zhang et al., 2003) and intrinsically by transcription factors (Wilson et al., 2004; Tothova et al., 2007; Reavie et al., 2010), cell cycle regulators (Cheng et al., 2000) and metabolic pathways (Nakada et al., 2010).

However, little is known about how HSCs are regulated at the post-translational level. The ubiquitin-dependent proteasome degradation system (UPS) is a primary mechanism that controls protein turnover and activation. UPS acts via three sequential enzymes: an E1 ubiquitin activating enzyme, an E2 ubiquitin conjugating enzyme and an E3 ubiquitin ligase (Crusio et al., 2010). Among these three enzymes, E3 ubiquitin ligases confer substrate specificity. An E3 ubiquitin ligase is a multi- 
eLife digest Stem cells can develop into other types of cells via a process called "differentiation". When a stem cell divides in two, it typically produces another stem cell and a cell that goes on to differentiate. Hematopoietic stem cells (or HSCs) are found in the bone marrow and give rise to all blood cells throughout the life of an organism. It is therefore crucial that they divide correctly to maintain the balance between renewing their numbers and making new types of cells.

Many studies have investigated how stem cells are maintained, but there are still major gaps in our knowledge. Recent research suggested that the cell's "ubiquitin-proteasome system" might be important for regulating stem cell division. This system rapidly degrades proteins, thereby regulating protein abundance in cells. Enzymes known as E3 ligases form part of this system, and recognize proteins to be marked for destruction with a small protein tag.

Gao et al. have now observed that a component of an E3 ligase called DDB1 is highly expressed in hematopoietic stem cells. Further experiments revealed that genetically engineered mice that lack DDB1 in their population of blood cells die soon after they are born and have fewer blood cells. Gao et al. next inhibited the production of DDB1 in adult mice. This stopped the adult mice's hematopoietic stem cells from dividing, and the mice died because their bone marrow couldn't produce new blood cells. These results show that DDB1 is necessary for stem cells to renew their numbers and differentiate into blood cells in both developing and adult animals.

Next, Gao et al. investigated the how DDB1 regulates stem cell division, and discovered that a protein called p53, which is a key player in controlling cell division, is regulated by DDB1. Under normal conditions, p53 levels are kept low in cells. However, in the absence of DDB1, the levels of p53 rise, which triggers the death of the hematopoietic stem cells.

Further experiments revealed that not all dividing cells undergo cell death with the loss of DDB1. Instead, Gao et al. found that rapidly dividing embryonic stem cells differentiate when DDB1 is lost but do not die. These findings suggest that specific components of the ubiquitin ligase complex play a key role in deciding a stem cell's fate. In the future, identifying these components will further our understanding of the decision of stem cells to differentiate.

DOI: 10.7554/eLife.07539.002

subunit complex that recognizes and binds specific target proteins via substrate recognizing subunits. In HSCs, it has been shown that Fbw7, an E3 ubiquitin ligase member, governs quiescence of HSCs (Matsuoka et al., 2008; Thompson et al., 2008). Itch and $\mathrm{c}-\mathrm{Cbl}$, other two E3 ubiquitin ligases, have been reported to negatively regulate HSC homeostasis and function (Rathinam et al., 2008; Rathinam et al., 2011). In other stem cell systems, it has been shown that Huwe1, a HECT domain containing E3 ubiquitin ligase, regulates proliferation and differentiation of neural progenitor cells as well as embryonic stem cells (ESC) (D'Arca et al., 2010). Protein levels of OCT4 and NANOG, transcription factors required for pluripotency, are modulated in an ubiquitin-dependent manner (Xu et al., 2009; Ramakrishna et al., 2011; Buckley et al., 2012), suggesting key roles of E3 ligase complexes for ESC differentiation. Recently we mapped the ubiquitinated protein landscape in mouse ESC and identified critical UPS members regulating ESC pluripotency and differentiation (Buckley et al., 2012).

DNA damage binding protein 1 (Ddb1), a component of the Cullin4-containing E3 ubiquitin ligase, was originally identified as a protein involved in the nucleotide excision repair pathway. DDB1 heterodimerizes with DDB2 and shows high affinity for UV-induced DNA damage sites (Batty et alo, 2000). Once bound to a damaged site, the CUL4-DDB1 complex ubiquitinates DDB2 and targets it for degradation, facilitating subsequent repair events (Sugasawa et alo, 2005). The CUL4-DDB1 ligase is a multi-component complex. Through its C-terminus, CUL4A or CUL4B binds to the RING finger protein to interact with the E2 conjugating enzyme. On its N-terminus, CUL4A or CUL4B binds to DDB1 to recruit CUL4-DDB1 associated factors (DCAF), a family of WD40 repeat proteins which confer substrate specificity (Angers et al., 2006; He et al., 2006; Higa et al., 2006). The CUL4-DDB1 ligase has been shown to target several substrates for ubiquitin dependent degradation. The list of substrates include the DNA replication licensing factor Cdt1 (Higa et alo, 2003; Hu et al., 2004), the cell cycle inhibitor p $27^{\text {Kip } 1}$ (Bondar et alo, 2006) and Cdkn1 $a^{C i p 1}$ (Abbas et al。, 2008; Nishitani et al., 2008), the histone methyltransferase PR-Set7 (Oda et alı, 2010; 
Tardat et al., 2010), and Epe1, a JmjC domain-containing histone demethylase in fission yeast (Braun et al., 2011). More recently it has been found that the CUL4-DDB1 complex can be modulated by binding of the drug, lenalidomide leading to degradation of lymphoid transcription factors IKZF1 and IKF3 in multiple myeloma cells (Fischer et al., 2014; Kronke et al., 2014). These findings suggest that the CUL4-DDB1 ligase complex has numerous substrates that it affects a variety of cellular functions, and that the complex can be altered with targeted therapeutics. Intriguingly, germline Cul4a deleted mice are viable and display no gross abnormality (Liu et al., 2009), possibly due to redundancy with $\mathrm{Cul} 4 \mathrm{~b}$, whereas Ddb1 deletion is embryonic lethal and embryos are not seen past E12.5 (Cang et al., 2006). Conditional inactivation of Cul4a in the skin leads to resistance to UV-induced skin carcinogenesis (Liu et al., 2009). Specific deletion of Ddb1 in brain results in elimination of neuronal progenitor cells, hemorrhages in brain, and neonatal lethality (Cang et al., 2006). DDB1 also plays a role in ESC self-renewal, and silencing of Ddb1 led ESC to differentiate (Buckley et al., 2012).

To investigate the role of the DDB1 in hematopoietic stem cells, we inactivated the Ddb1 gene in hematopoietic stem and progenitor cells (HSPC) and at different developmental stages. Here we report that Ddb1 loss impairs HSPC function in both the adult bone marrow and the fetal liver. More specifically, Ddb1 deletion leads to induction of DNA damage, rapid induction of apoptosis, and Trp53 response, resulting in bone marrow failure and acute lethality. However, deletion of Ddb1 had no effect on resting mature lymphoid cells and whereas in proliferating embryonic stem cells (ESC) silencing of Ddb1 led to loss of pluripotency without effects on cell survival. Our results demonstrate CUL4-DDB1 is a novel regulator of stem cell homeostasis.

\section{Results}

\section{Fetal hematopoiesis is absolutely dependent on Ddb1 function}

To study the role of distinct ubiquitin ligases in the biology of HSCs, we initially performed a metaanalysis of genome-wide expression in lineage ${ }^{-S} \mathrm{Ca}^{+}{ }^{+} \mathrm{CKit}^{+}$(LSK) cells, a population enriched for HSCs, and found several E3 ligases among the top $20 \%$ highly expressed genes, including the already reported HSC regulators Fbw7 (Thompson et al., 2008), Cul1, Itch (Rathinam et al., 2011) and c-Cbl (Rathinam et al., 2008) (Figure 1a). Both genes of the Cul4 ${ }^{D B 1}$ complex were also highly expressed in LSKs (Figure 1a), suggesting that this E3 complex could be important in early hematopoiesis. We further examined the expression of Ddb1 in long-term HSCs (LT-HSC, CD150 ${ }^{+}$ CD48-LSK) and downstream progenitor populations. It was found that Ddb1 was expressed at a low level in quiescent LT-HSCs, and significantly upregulated in multipotent progenitors (MPP, CD150-CD48 $\left.{ }^{+} \mathrm{LSK}\right)$, a proliferating progenitor subset. Ddb1 expression remained constant in later progenitor populations (Figure 1b). The expression pattern of Ddb1 suggests its potential role in hematopoiesis.

To investigate the importance of $D d b 1$ function in hematopoiesis, we generated $D d b 1^{f / f}:$ : Vav1Cre ${ }^{+}$mice. The Vav1 promoter drives the expression of Cre recombinase in entire hematopoietic compartment during embryonic development ( E13.5) from HSC and progenitors to mature cells. Efficient deletion of Ddb1 in bone marrow was confirmed by qPCR (Figure 2a). Ddb $1^{f / f}:$ : Vav1Cre ${ }^{+}$mice were born at normal frequencies and were indistinguishable from littermates. However, $D d b 1^{f / f}:: V a v 1 C r e^{+}$animals died rapidly after birth (Figure 2 b). Peripheral blood analysis at day 7 showed that $D d b 1^{f / f}:: V a v 1 C r e^{+}$mice had significantly decreased counts of white blood cells, red blood cells and platelets compared to littermates (Figure $2 c, d$ ). Moreover, the cellularity and size of thymus and spleen were significantly reduced (Figure $2 e, f$ ). When analyzed by flow cytometry, lineage ${ }^{-} \mathrm{Sca}{ }^{+} \mathrm{CKit}^{+}$(LSK) cells, a population enriched for HSCs, and $\mathrm{cKit}^{+}$progenitors were undetectable (Figure $2 \mathrm{~g}$ ). Mature lymphoid $\left(\mathrm{CD} 4^{+} \mathrm{CD} 8^{+}\right.$in thymus, $\mathrm{B}_{2} 20^{+} \mathrm{IgM}^{+}$in spleen) and myeloid $\left(\mathrm{Gr} 1^{+}\right.$ $\mathrm{Mac}^{+}$in spleen) cells were severely reduced (Figure $2 \mathrm{~h}$ ). Since Vav1Cre expression starts as early as embryonic day 13.5 (E13.5) (Stadtfeld and Graf, 2005), we hypothesized that the pan-cytopenia in $D d b 1^{f / f}:: V a v 1 C r e^{+}$neonates was due to defects initiated during fetal hematopoiesis. Analysis of E16.5 fetal liver of $D d b 1^{f / f}:: V a v 1 C r e^{+}$mice showed that the deletion of Ddb1 in fetal hematopoietic cells led to reduction of the LSK and $\mathrm{CKit}^{+}$progenitors, as well as mature CD19 ${ }^{+}$B-lymphoid and $\mathrm{Gr}^{+}$myeloid cells (Figure 2i). Interestingly, the distribution of LT-HSC and MPP was skewed with higher frequency of LT-HSC and lower frequency of MPP cells (Figure 2i). Genome-wide gene 
a

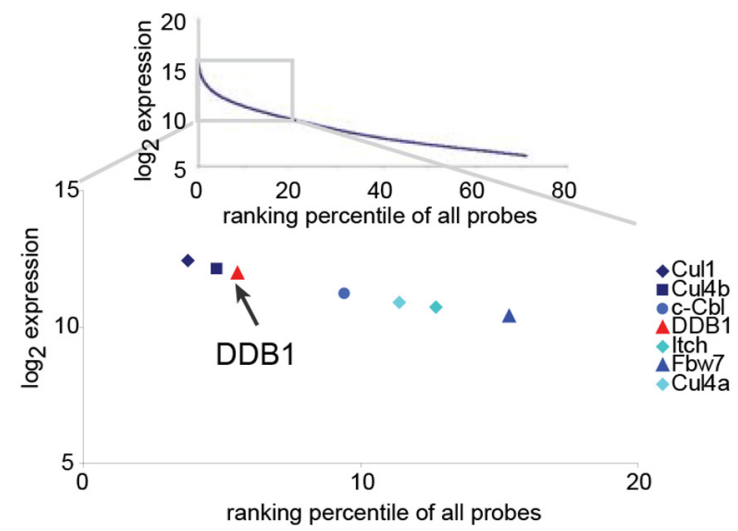

b

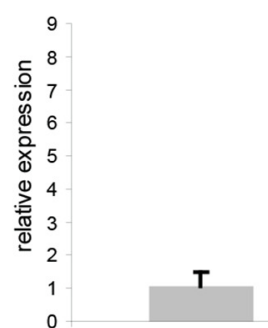

LT-HSC

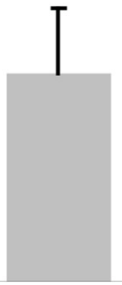

MPP

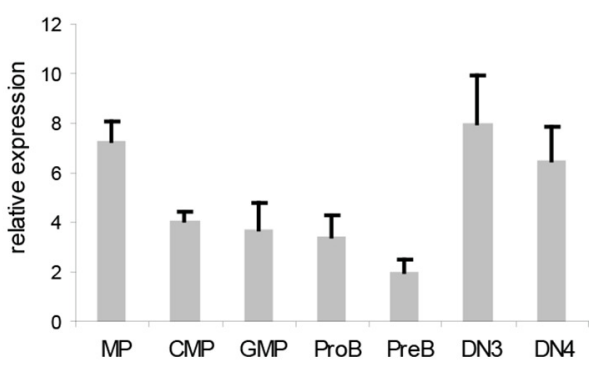

Figure 1. Ddb1 is highly expressed in the hematopoietic system. (a) Expression ranking of Cul4-Ddb1 components in LSKs compared to all probes available in microarray. Microarray was performed on LSK cells. The expression value of all probes were ranked from high to low. (b) Quantitative PCR of Ddb1 in hematopoietic populations. DOI: 10.7554/eLife.07539.003

expression analysis revealed that Ddb1-deficient LSKs up-regulated genes associated with stem cell identity (Mecom, Thy1, Angpt1) and down-regulated genes associated with differentiation (Figure $2 \mathbf{j}, \mathbf{k}$ ), consistent with the phenotypic enrichment of the HSC population. Overall, our data demonstrate that Ddb1-deletion leads to cytopenia and neonatal lethality, confirming that Ddb1 expression is absolutely required for fetal hematopoiesis.

\section{Deletion of Ddb1 in adult hematopoietic cells leads to bone marrow failure}

To circumvent the neonatal lethality of $D d b 1^{f / f}:: V a v 1 C r e^{+}$mice, we turned to the $\mathrm{Mx} 1 \mathrm{Cre}$ strain that can be induced to delete the target gene. In $D d b 1^{f / f}:: M x 1 C r e^{+}$mice, Ddb1 was deleted in hematopoietic compartment of adult mice by injecting polyinosine-polycytidine (polyl:C) to induce interferon $\alpha$ response. The floxed allele of Ddb1 was recombined efficiently after polyl:C injection in all hematopoietic tissues including the bone marrow (Figure 3a). As a result, the Ddb1 protein was undetectable in polyl:C injected $D d b 1^{f / f}:: M x 1 C r e^{+}$bone marrow (Figure $3 b$ ). Strikingly, all $D d b 1^{f / f}::$ $\mathrm{Mx} 1 \mathrm{Cre}^{+}$animals died within 3 weeks post Ddb1 deletion (Figure $3 \mathrm{c}$ ). To investigate the cause of the lethality, we analyzed Ddb1 deficient mice 7 days after polyl:C injection. Peripheral blood counts showed that the Ddb1 loss resulted in significant reduction in the total number of white blood cells and platelets (Figure 3d). No reduction was found in red blood cells, however enucleated red blood cells have a half-life of approximately 40 days suggesting DDB1 deficient mice succumb to hematopoietic failure prior to red blood cell turnover. $\mathrm{Ddb} 1^{\mathrm{f} / \mathrm{f}}: \mathrm{M} \times 1 \mathrm{Cre} \mathrm{C}^{+}$bone marrow hypo-cellularity was evident from histological examination (Figure 3e), which was mostly accounted by cellularity decrease of myeloid lineage (Figure $3 \mathrm{f}, \mathrm{g}$ ). To understand the kinetics of Ddb1 deletion effects, we analyzed HSC and progenitor cells at different time points after Ddb1 deletion. cKit+ progenitors 


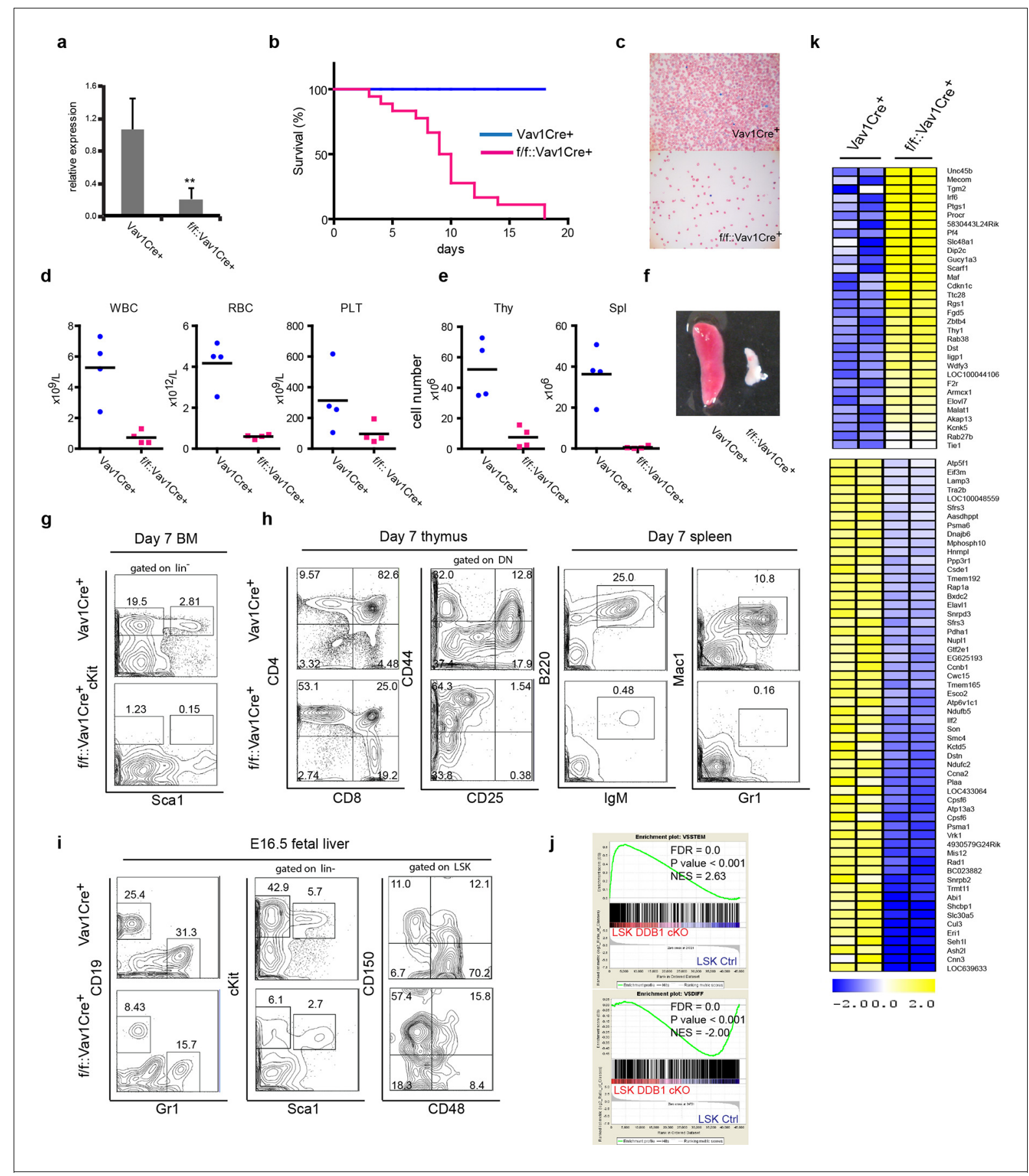

Figure 2. Abrogation of fetal hematopoiesis in $D d b 1^{f / f}$ Vav1Cre ${ }^{+}$mice. (a) Quantitative PCR of Ddb1 in control and Ddb $1^{f / f}:$ Vav1Cre ${ }^{+}$mice. (b) Survival curves of control and Ddb1 $1^{f / f}:$ Vav1Cre ${ }^{+}$mice ( $n=18$ per group). (c) Giemsa staining of peripheral blood smears from 7-day old mice. (d) Peripheral blood counts in 7-day old mice ( $n=4$ per group). WBC: white blood cells $(p=0.0054)$. RBC: red blood cells $(p=0.0007)$. PLT: platelets $(p=0.10)$. Black bar indicates average. (e) Total cell numbers in thymi $(p=0.0050)$ and spleens $(p=0.0016)$ of 7 -day old mice $(n=4$ per group). Black bar indicates average. $(f)$ Representative pictures of spleens from 7-day old mice. (g) Representative FACS plots of bone marrow of 7-day old mice. (h) Representative FACS plots of thymi and spleens of 7-day old mice. ( $N=3$ ). (i) Representative FACS plots of fetal livers at embryonic day 16.5. ( $n=3$ ) (j) Gene set enrichment analysis (GSEA) of gene expression analysis performed on fetal LSKs at embryonic day 16.5. (k) Heatmap of gene expression analysis performed on fetal LSKs at embryonic day 16.5. ${ }^{*} p<0.05 .{ }^{* \star} p<0.01 .{ }^{* \star *} p<0.001$.

DOI: 10.7554/eLife.07539.004

(both MP and LSK) were decreased in cell number at day 5 and further more at day 7 (Figure $3 \mathrm{~h}, \mathrm{i})$. We used the SLAM markers (CD150 and CD48) to further characterize the long-term HSCs (LT-HSC, 


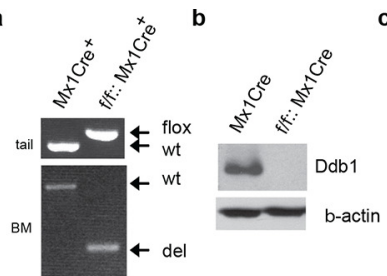

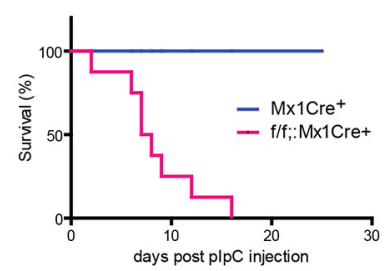

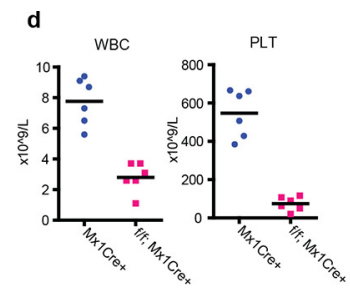

e

f
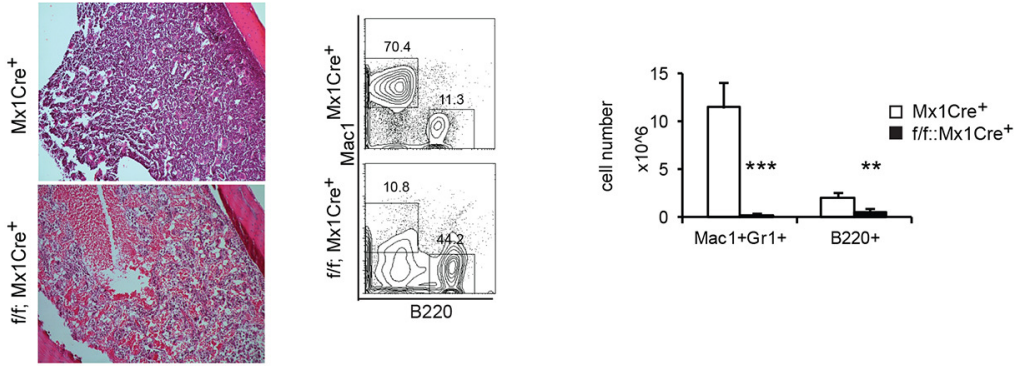

h
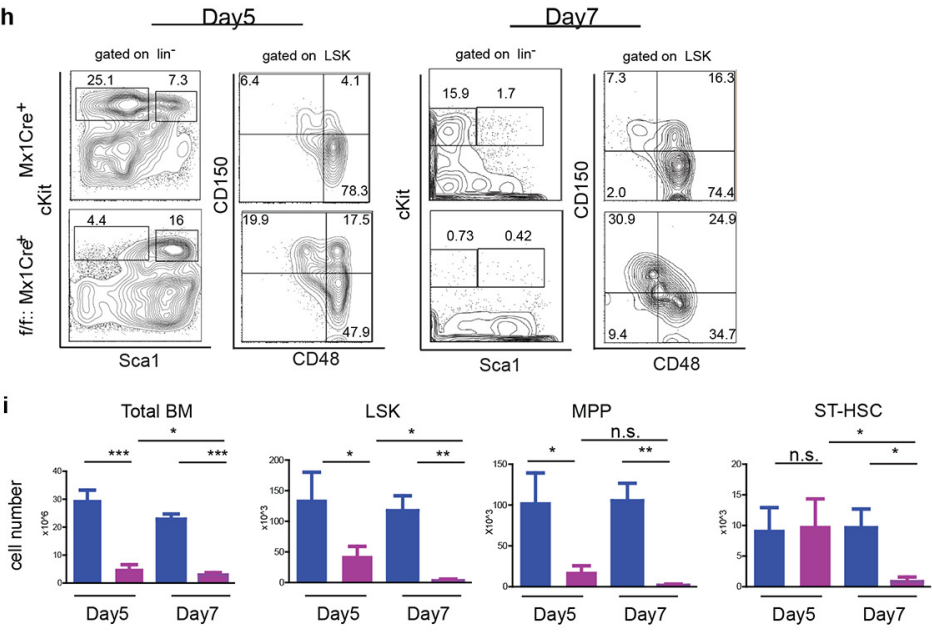

j 120
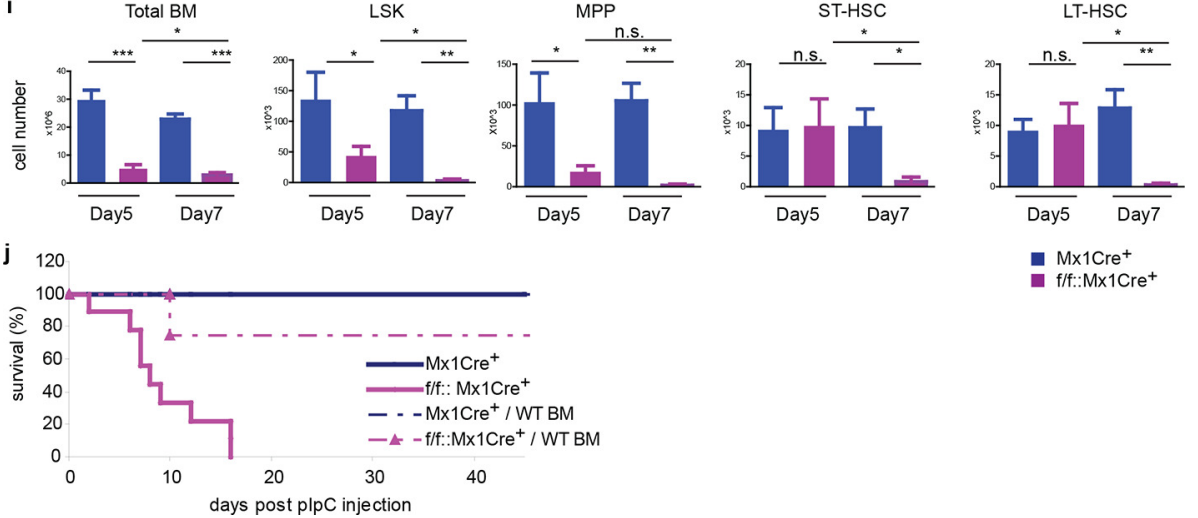

Figure 3. Deletion of $D d b 1$ in $D d b 1^{f f f}:: M \times 1 C r e^{+}$mice leads to bone marrow failure and acute lethality. (a) PCR on genomic DNA from tail or polyl:C injected bone marrow to detect wild type (wt), "floxed" (flox) and recombined (del) alleles of Ddb1 locus. (b) Western blot of bone marrow cells from polyl:C injected animals. (c) Survival curve of mice after polyl:C injection ( $n=8$ per group). (d) Peripheral blood counts 7 days after polyl:C injection $(n=$ 6 per group). (WBC and PLT $p=<0.0001$ ). Black bar indicates average. (e) H\&E staining of tibia sections 7 days after polyl:C injection. (f) Representative FACS plots of bone marrow cells. (g) Cellularity of bone marrow 7 days after poly:C injection. $N=5$ per group. (h) Representative FACS plots of bone marrow cells after polyl:C injection. (i) Cell numbers of total bone marrow and stem and progenitor cell populations in mice after polyl:C injection $(n=5$ per group). ${ }^{*} p<0.05$. ${ }^{* \star} p<0.01$. ${ }^{* \star *} p<0.001$. (j) Non-polyl:C injected $\mathrm{Ddb} 1^{f / f}:: \mathrm{M} \times 1 \mathrm{Cre}^{+}$mice were lethally irradiated and transplanted with wild type bone marrows. Eight weeks after engraftment, DDB1 deletion was induced by polyl:C injection. Survival of these chimera mice ( $N=4$ per group) was followed and compared to polyl:C injected Ddb $1^{f / f}:: \mathrm{M} \times 1 \mathrm{Cre}^{+}$mice.

DOI: 10.7554/eLife.07539.005

$\mathrm{CD} 150^{+} \mathrm{CD} 48-\mathrm{LSK}$ ), short-term HSCs (ST-HSC, CD150 ${ }^{+} \mathrm{CD} 48^{+} \mathrm{LSK}$ ) and multipotent progenitors (MPP, CD150 CD48 ${ }^{+}$LSK) populations. It was found that the frequencies of LT-HSC, ST-HSC and 
MPP subsets were distorted upon Ddb1 deletion, as there was a significant relative over-representation of LT-HSCs (Figure $3 \mathrm{~h}$ ), similar to the findings in fetal hematopoiesis. In terms of cell number, MPPs, but not ST- and LT-HSCs, were decreased at day5, which was followed by the decrease of all HSPCs subsets at day7 (Figure $3 \mathrm{~h}$ ). This data suggest that Ddb1 deletion has a greater impact on proliferative populations, in agreement to the expression analysis presented earlier. Together, these results demonstrate that the deletion of Ddb1 leads to acute loss of proliferating HSPCs and their downstream progeny, resulting in bone marrow failure and lethality.

The Cre recombinase under control of the $M \times 1$ promoter is also expressed in other IFN $\alpha$-responsive tissues besides hematopoietic cells, including the liver, lungs, and heart (Kuhn et al., 1995), however no gross abnormality was found in $D d b 1^{f / f}:: M x 1 C r e^{+}$mice at the time-point of the analysis (data not shown). To further establish that Ddb1 deficient mice died of bone marrow failure, we transplanted wild type bone marrow cells into lethally irradiated non-polyl:C injected $D d b 1^{f / f}:$ : $\mathrm{Mx} 1 \mathrm{Cre}^{+}$and control mice. Eight weeks after bone marrow transplant, polyl: $\mathrm{C}$ was injected into the transplanted recipient mice to induce Ddb1 deletion. In this case, the majority of chimeric $D d b 1^{f / f}::$ $\mathrm{Mx} 1 \mathrm{Cre}^{+}$mice survived significantly longer than Ddb1 deficient mice (Figure 3j), strongly suggesting that the acute lethality observed in polyl:C injected $D d b 1^{f / f}:: M \times 1 C r e^{+}$mice is due to bone marrow ablation.

\section{Ddb1 deficiency impairs differentiation of hematopoietic stem and progenitor cells}

Next, we further addressed the function of the DDB1-deleted progenitors and stem cells both in vitro and in vivo Initially, methylcellulose cultures and CFU-S assays were performed to test the differentiation function of DDB1 deficient HSPCs. Strikingly, DDB1 deficient bone marrow cells from polyl:C injected $D d b 1^{f / f}:: M x 1 C r e^{+}$animals were not able to form colonies in cytokine-supplemented in vitro culture as well as in spleens of host mice (Figure $4 a, b$ ). Identical results were obtained when we deleted Ddb1 in progenitor cells using a Cre-expressing retrovirus (Figure 4c). These data reveal that Ddb1 deletion impairs differentiation ability of the HSC and progenitor cells. HSC function is assayed by bone marrow transplantation (BMT). To this end, we transplanted DDB1 deficient bone marrow cells and littermate control cells into lethally irradiated recipient mice. All mice receiving Ddb1 deficient cells died within 3 weeks post BMT while those receiving control cells had a normal life span (Figure $4 d$ ), indicating that Ddb1 deficient cells are not able to repopulate the hematopoietic system.

To rule out non-cell autonomous effects of Ddb1 deletion (i.e. effects in HSC niches), we transplanted cells from non-polyl:C injected $D d b 1^{f / f}:: M x 1 C r e^{+}$mice into lethally irradiated wild type recipient mice. Eight weeks after engraftment, polyl:C was injected into the recipients to induce the Ddb1 deletion in hematopoietic cells of the recipients. DDB1-deficient cells (CD45.2 ${ }^{+}$) lost representation (Figure $4 e$ ). Similar to non-transplant settings, $\mathrm{cKit}^{+}$progenitors and stem cells derived from DDB1 deficient donor cells were significantly reduced and more apoptotic as shown by AnnexinV/ 7AAD staining (Figure 4e). These results further prove that the effects of Ddb1 deletion on HSPC are cell-autonomous.

Next, we performed competitive BMT. Ddb $1^{\mathrm{f} f}:: \mathrm{Mx} 1 \mathrm{Cre}^{+}$and control bone marrow cells $\left(C D 45.2^{+}\right)$were mixed with equal number of wild type counterparts (CD45. $1^{+}$) and transplanted into lethally irradiated recipients. Eight weeks after engraftment, polyl:C was injected into the recipients to induce $D d b 1$ deletion. Peripheral blood of the recipients was analyzed at different time points after the Ddb1 deletion. Control cells maintained CD45.2 $2^{+}$chimerism through out the time course of the analysis. However, DDB1-deficinet cells were not able to compete with wild type counterparts (Figure 4f). DDB1-deficient myeloid cells $\left(\mathrm{Mac} 1^{+} \mathrm{Gr} 1^{+}\right.$) were significantly reduced compared to wild type cells as early as 2 weeks after the Ddb1 deletion. DDB1-deficient lymphoid cells $\left(\mathrm{CD}^{+}{ }^{+}\right.$and $\mathrm{B}_{2} 2 \mathrm{O}^{+}$) were also reduced with slower kinetics (Figure 4f). These data suggest that Ddb1 deletion specifically targets expanding progenitors and highly proliferating cells inhibiting the stem and progenitor populations to replenish the hematopoietic system.

\section{Ddb1 phenotypes are partially dependent on Trp53 pathway activity}

To gain further insights into DDB1-mediated mechanisms of action, we examined apoptosis status on whole tibia section by TUNEL analysis. We found that DDB1-deficient bone marrow displayed 
a

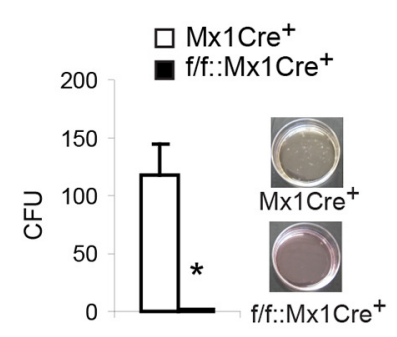

b

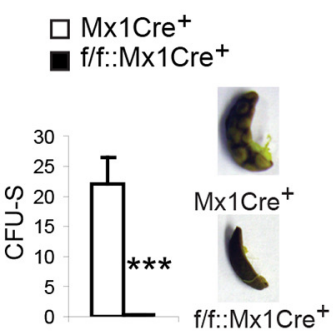

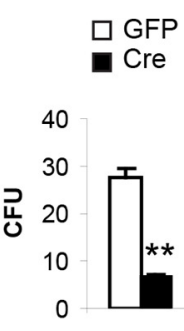

d

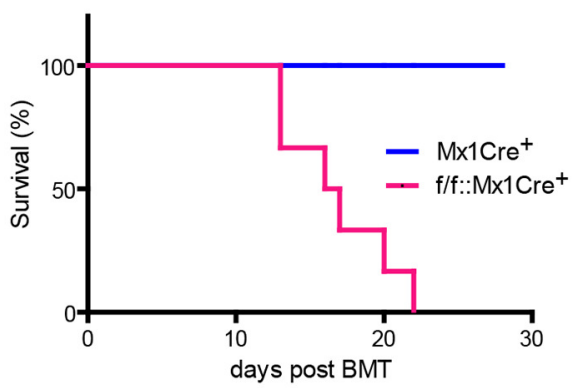

e
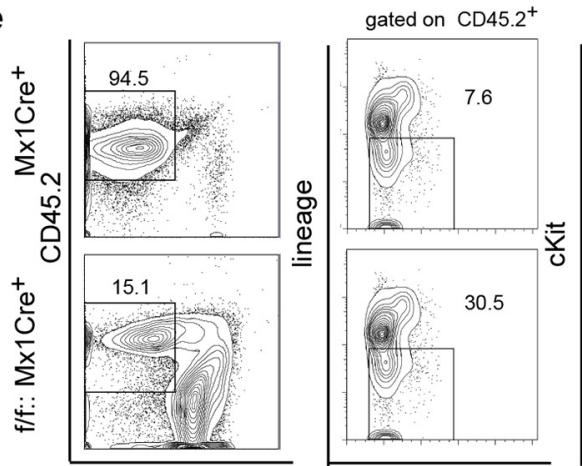

FSC

CD45.1

f
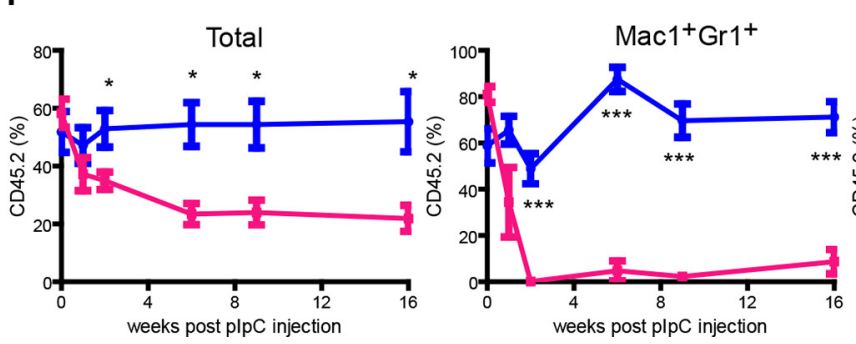

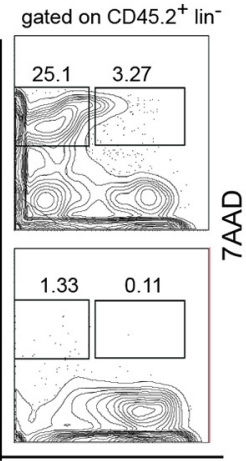

Sca1

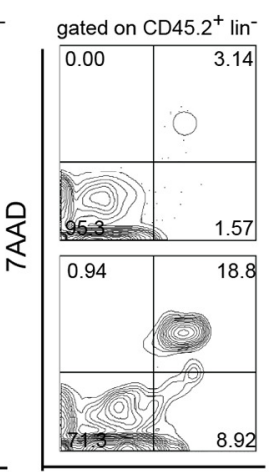

AnnV $\rightarrow \mathrm{Mx} 1 \mathrm{Cre}^{+}$ $=\mathrm{f} / \mathrm{f}: \mathrm{Mx} 1 \mathrm{Cre}^{+}$

Figure 4. Ddb1 deletion impairs the differentiation of hematopoietic stem and progenitor cells. (a) Colony numbers and representative images from methylcellulose assay with bone marrow cells from polyl:C injected mice. (b) Colony numbers and representative images from CFU-S assay with bone marrow cells from polyl:C injected mice. (c) Bone marrow progenitor cells of $D d b 1^{f / f}:: M x 1 C r e^{+}$mice were infected with retrovirus expressing either control GFP or Cre recombinase. Colony numbers were scored in methylcellulose assays. (d) Survival curve of recipient mice after bone marrow transplantation ( $n=6$ per group). Donor cells were from Ddb $1^{f / f}:: M \times 1 C r e^{+}$or control mice injected with polyl:C. (e) Representative FACS plots of bone marrow cells in recipient mice 7 days post Ddb1 deletion. Donor cells were from non polyl:C injected mice, and Ddb1 deletion was induced in recipient mice 8 weeks after engraftment. (f) Chimerism of peripheral blood in recipient mice ( $n=5$ per group). Donor cells were a mixture at $50: 50$ ratios of wild

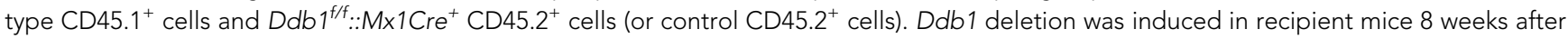
engraftment. ${ }^{*} \mathrm{p}<0.05$. ${ }^{* *} \mathrm{p}<0.01$. ${ }^{* * *} \mathrm{p}<0.001$

DOI: $10.7554 /$ LLife. 07539.006

significant apoptosis (Figure 5a). More specifically, we found that DDB1-deficient progenitors (both LSKs and MPs) were more apoptotic as shown by the AnnexinV staining, but not lineage ${ }^{+}$cells (Figure 5b). In line with these results, DDB1-deficient progenitor cells had elevated protein levels of phospho-Trp53, the activated form of Trp53. In addition, cyclin-dependent kinase inhibitor 1A $\left(\mathrm{Cdkn1} \mathrm{a}^{\mathrm{Cip} 1}\right)$, a transcription target of Trp53, was accumulated at the protein and mRNA levels (Figure $5 c, d$ ). Signs of DNA damage were also observed in Ddb1-deficient LT-, ST-HSCs and MPPs, but not in lineage ${ }^{+}$cells, as revealed by $\gamma \mathrm{H} 2 \mathrm{Ax}$ staining, a marker for double strand DNA breaks as well as by 53BP1 foci (Figure 5e,f). Collectively these results demonstrate that Ddb1 deletion leads to DNA damage, rapid apoptosis and Trp53 pathway activation in HSPCs.

To access whether Ddb1 hematopoietic phenotypes were dependent on Trp53 activity, we generated $\operatorname{Trp} 53^{-/-}:: D d b 1^{f / f}:: M x 1 \mathrm{Cre}^{+}$mice and examined stem and progenitor subsets. In the 

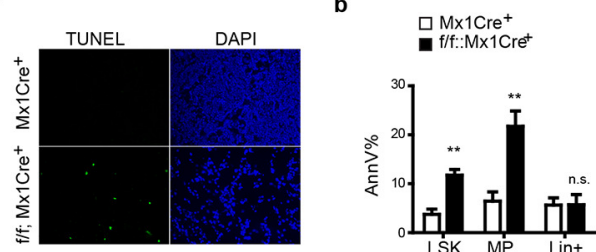

c

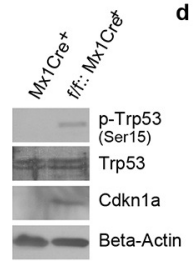

d

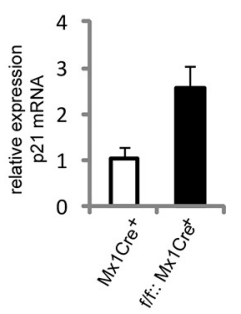

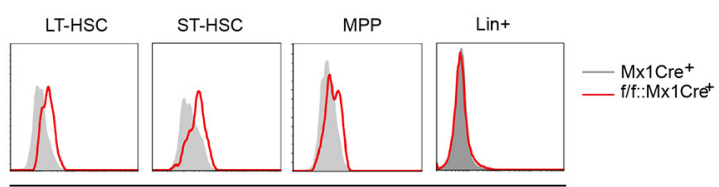

i.c. $\gamma \mathrm{H} 2 \mathrm{Ax}$

f

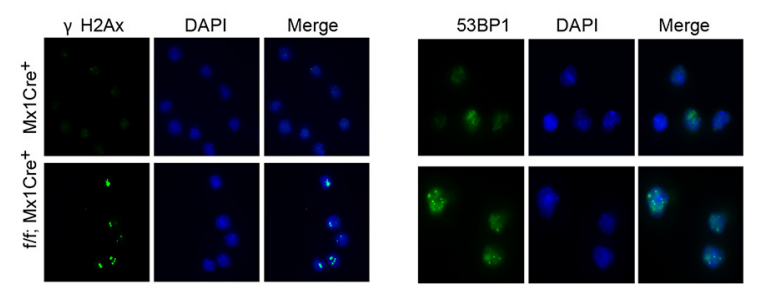

g

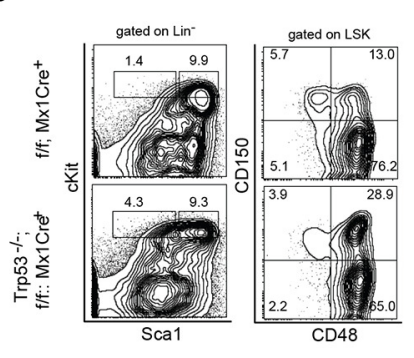

i

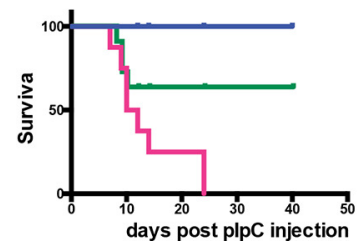

h

h LT-LSK
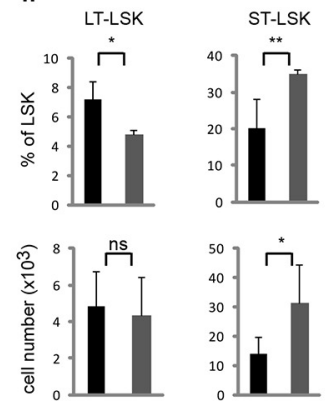

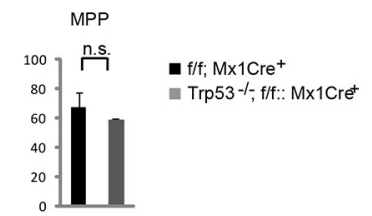

$\left.\begin{array}{c}100 \\ 80 \\ 60 \\ 40 \\ 20 \\ 0\end{array}\right]$ I I I

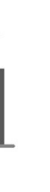

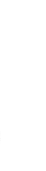

Control

_- Trp53-/:-: f/f::Mx1Cret

Figure 5. Ddb1 deletion induces DNA damage and apoptosis in progenitor cells. (a) TUNEL staining on tibia sections after polyl:C injection. (b)

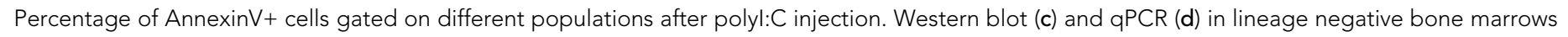

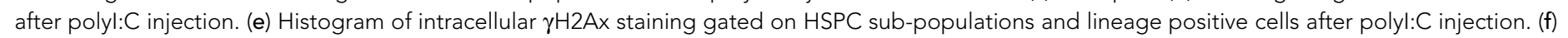

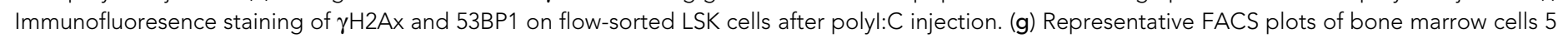

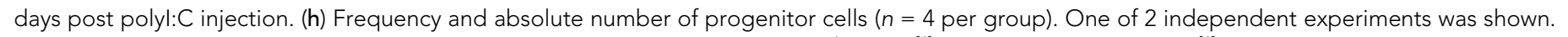

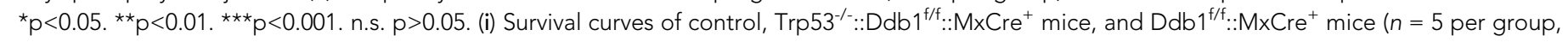
one independent experiment). Age matched littermates on a mixed 129xC57BL/6 background were used for g-i.

hematopoietic system, Trp53 deletion partially rescued the $D d b 1^{-1 /}$ phenotype (Figure $\left.5 \mathbf{g}, \mathbf{h}, \mathbf{i}\right)$. Both the percentage and absolute number of ST-HSC $\left(\mathrm{CD} 150^{+} \mathrm{CD} 48^{+} \mathrm{LSK}\right)$, but not LT-HSC and MPP, were increased in $\operatorname{Trp} 53^{-1}:: D d b 1^{f / f}:: M \times 1 C r e^{+}$compared with Ddb1f/f::Mx1Cre animals (Figure $5 \mathrm{~g}$, h). These results suggest that Trp53 activation takes place in response to Ddb1 deletion but this activation does not account for the full spectrum of the phenotype. 


\section{DDB1 is dispensable for the maintenance of mature T cells}

Next, we examined whether the abrogated hematopoiesis resulted from Ddb1 silencing was specific for stem/progenitor cells. To this end, Ddb1 was conditionally deleted in mature $T$ cells using the Cd4Cre ${ }^{+}$strain. In this mouse model, Cre recombinase expression initiates at the $\mathrm{CD} 4{ }^{+} \mathrm{CD} 8^{+} \mathrm{T}$ lymphocyte stage of development, a population characterized by minimal cell proliferation. DDB1 was efficiently deleted at protein and mRNA levels in total thymocytes (Figure $6 a, b$ ). The residual Ddb1 expression in total thymocytes could be attributed to the existence of DN cells in which the Cre recombinase was not expressed. We then examined T cell profiles in thymi and peripheral lymphoid tissue of $D d b 1^{F / F}:: C d 4 C r e^{+}$mice. We found that these mice had normal thymocyte numbers (Figure $6 \mathrm{c}$ ), and normal CD4/CD8 cell profiles (Figure $6 \mathrm{~d}$ ), confirming our hypothesis that Ddb1 deletion in mature/resting $T$ cells did not affect $T$ cell development. To test this hypothesis further, we stimulated peripheral $\mathrm{CD}^{+}$cells using anti-CD3/CD28 treatment in vitro. When activated, the control T cells entered cell cycle, incorporated BrdU, an analogue of thymidine which is incorporated during DNA synthesis, and underwent several rounds of cell division as shown by the dilution of CFSE labeling. Strikingly, the DDB1 deficient $\mathrm{CD}^{+}$cells failed to proliferate (Figure 6e). Instead, more AnnexinV positive cells were found in the culture of DDB1-deficient CD4 ${ }^{+}$cells (Figure 6f), suggesting induction of cell death. Furthermore, we labeled anti-CD3/CD28 treated cells with EdU, an alternative of BrdU and easier for detection by immunoflourescence, and found that there were once more significantly fewer cells incorporating EdU when Ddb1 was deleted (Figure 6g,h), suggesting Ddb1 deletion interferes with cell cycle progression. Combination of BrdU and DAPI labeling clearly showed that, when stimulated to proliferate, DDB1 deficient resting cells were unable to enter $\mathrm{S}$ phase of the cell cycle. Consistent with this result, the $\mathrm{Cdkn} 1 \mathrm{a}^{\text {cip } 1}$ protein, a potent CDK and cell cycle inhibitor, was accumulated in DDB1-deficient cells at the protein level, but not mRNA level (Figure $6 \mathrm{i}, j$ ). When proteasome-dependent protein degradation was inhibited by MG132, Cdkn1acip1 was significantly accumulated in control cells, however less protein accumulation following proteasome inhibition was seen in DDB1-deficient cells (Figure 6i), demonstrating that Cdkn1a cip1 degradation is dependent on DDB1 function. To prove direct interaction, Cdkn1a $a^{\text {cip } 1}$ was co-immunoprecipitated with Cul4 and DDB1 complex (Figure 7a), suggesting that Cdkn1 $a^{\text {cip } 1}$ is indeed a substrate of Cul4a $a^{\mathrm{DDB} 1}$. In contrary, p27 ${ }^{\mathrm{kip} 1}$, another cell cycle inhibitor and suggested DDB1 substrate (Bondar et al., 2006), was not co-immuno-precipitated with the CUL4 ${ }^{\text {DDB1 }}$ complex (Figure 7b). The above observation led us to test the hypothesis whether DDB1-deficiect phenotype in HSPCs can be restored by silencing Cdkn1 $a^{\text {cip }}$. To this end, Cdkn1 $a^{-/-}$mice were crossed to $D d b 1^{f / f}:: M x 1 C r e^{+}$and polyl:C was administered. We did not observe the restoration of stem or progenitor cell numbers (Figure 7c). Overall, these data demonstrate that DDB1 function is dispensable for resting T-lymphocyte homeostasis but becomes pivotal when cells enter S phase of the cell cycle.

\section{DDB1 is required for embryonic stem cell pluripotency}

Due to the striking consequences of loss of DDB1 on the HSPC proliferation and survival, but not on definitive differentiated populations, we sought to determine the effects of Ddb1 on an additional stem cell population, and more specifically in embryonic stem cells (ESC). ESC are highly proliferative and can differentiate into cell lineages of all three germ layers. We recently reported that pluripotency and differentiation of mouse embryonic stem cells (ESC) are regulated at the post-translational level by the ubiquitin-proteasome systems (UPS). Ddb1 was identified as one of the regulators essential for ESC self-renewal in a large interference RNA (siRNA) screen against USP members. Depletion of Ddb1 resulted in loss of ESC self-renewal and pluripotency (Buckley et al., 2012). Here, we further validated the loss-of-function effects of Ddb1 on ESC using two distinct shRNAs. Consistent with our previous findings, silencing Ddb1 by shRNAs led to loss of ESC colony morphology (Figure 8a) and down-regulation of pluripotency factors Nanog and Oct4, and up-regulation of genes associated with mesoderm (Meox1), ectoderm (Gfap), and endoderm (Sox17) early differentiation (Figure $8 \mathrm{~b}, \mathrm{c}$ ). However, we did not observe aberrant cell cycle or significant change in rates of apoptosis in these cells (Figure $8 \mathrm{~d}, \mathrm{e}$ ). Similar to ESC differentiated in the presence of retinoic acid, total Trp53 protein increased following silencing of Ddb1 (Figure $8 \mathrm{c}$ ). These data demonstrate that DDB1 is essential for ESC pluripotency and self-renewal without being accompanied by increased apoptosis or defects in cell cycle kinetics. 


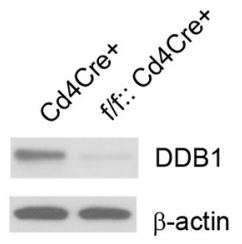

b

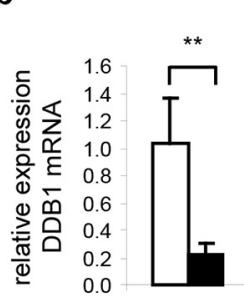

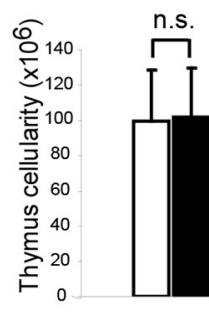

d

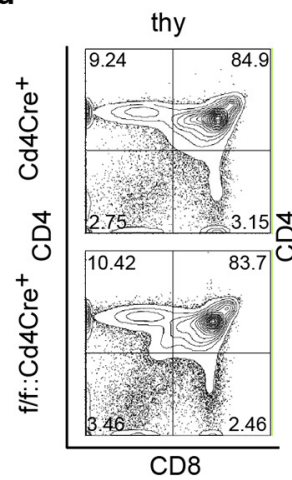

g

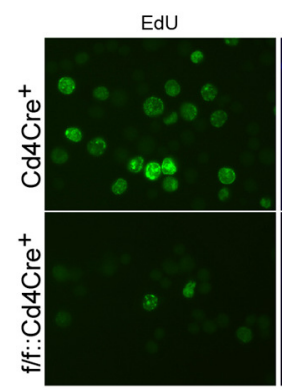

i

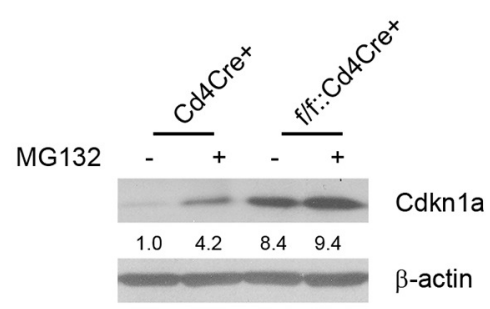

e

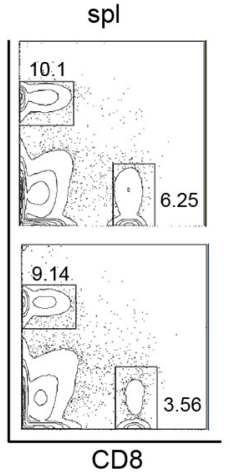

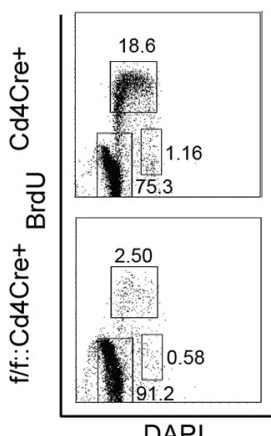

DAPI
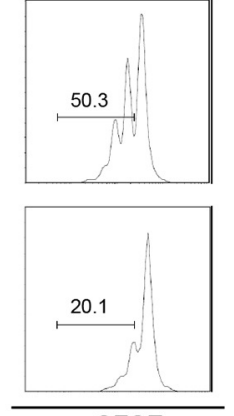

CFSE f

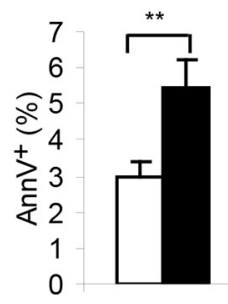

h
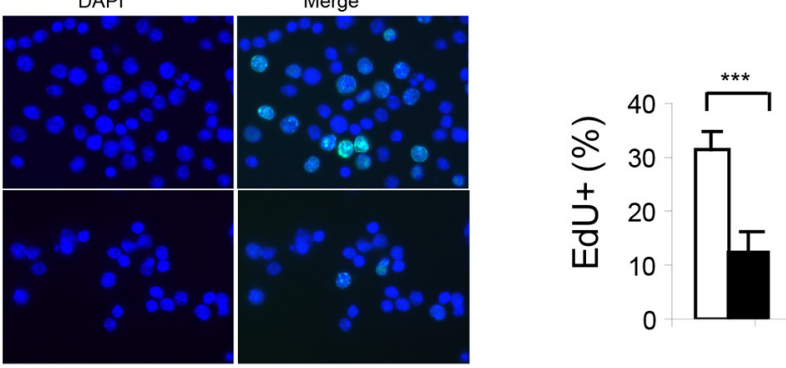

j

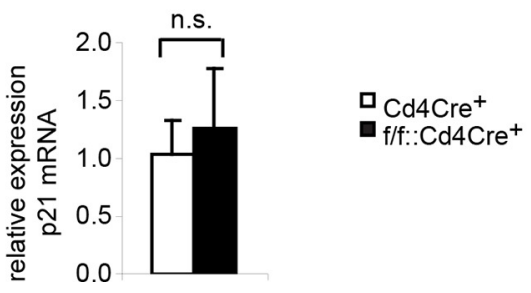

Figure 6. Ddb1 deletion is dispensable for mature T cells. (a) Western blot of DDB1 expression in total thymocytes. (b) Relative Ddb1 mRNA expression in thymocytes. (c) Total cell number of thymus of 6-week old mice $(n=4)$. (d) Representative FACS plots of thymus and spleen. (e) Spleen CD4 ${ }^{+}$cells were sorted and stimulated with $1 \mu \mathrm{g} / \mathrm{ml}$ anti-CD3/CD28 in vitro. BrdU incorporation and CFSE dilution was analyzed. (Anti-CD3/CD28 treated CD4 ${ }^{+}$ cells were stained for AnnexinV $V^{+}$by FACS and percentage of AnnexinV $V^{+}$cells was shown. (f) Anti-CD3/CD28 treated CD4 ${ }^{+}$cells were stained for AnnexinV $V^{+}$by FACS and percentage of AnnexinV ${ }^{+}$cells was shown. (g) Anti-CD3/CD28 treated CD4 ${ }^{+}$cells were labeled and stained with EdU. (h) Percentage of EdU ${ }^{+}$cells was shown. More than 300 cells were included in each analysis. (i) Spleen CD4 ${ }^{+}$cells were treated with $10 \mu \mathrm{M} \mathrm{MG132} \mathrm{for} 2 \mathrm{hr}$ and Western blot was performed. Relative Cdkn1 $a^{\text {cip } 1}$ protein levels normalized to $\beta$-actin were indicated below the corresponding lanes. (j) qPCR was performed on spleen $\mathrm{CD}^{+}$cell. Representative results of two independent experiments were shown. ${ }^{\star} p<0.05 .{ }^{\star \star} p<0.01 .{ }^{\star \star \star} p<0.001 . n . s$. $p>0.05$. DOI: 10.7554/eLife.07539.008 
a

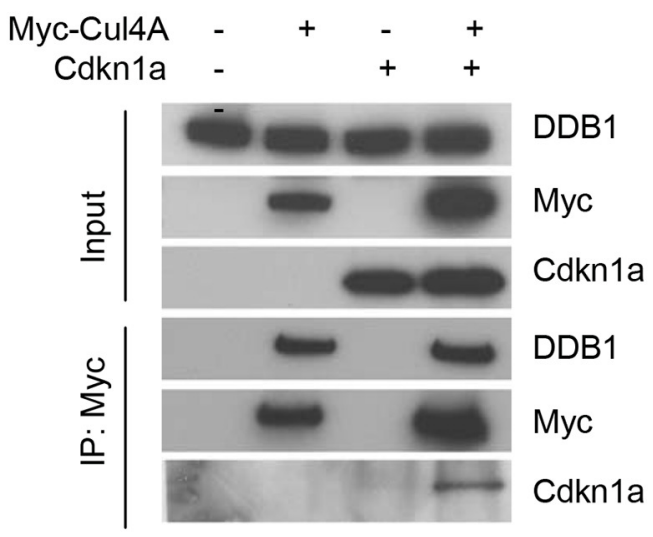

b

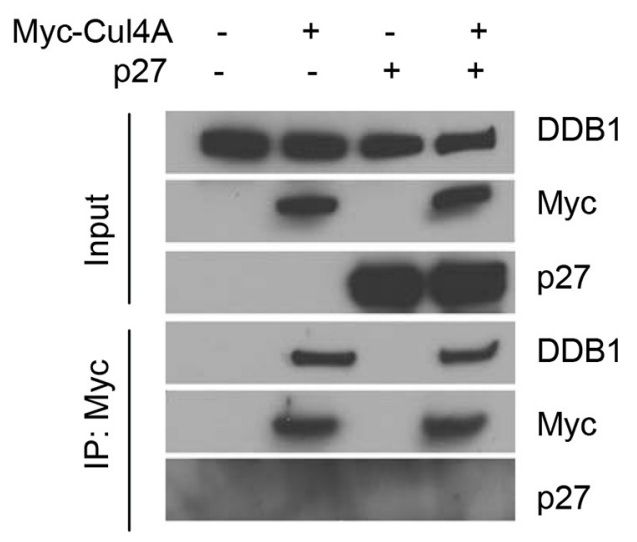

C

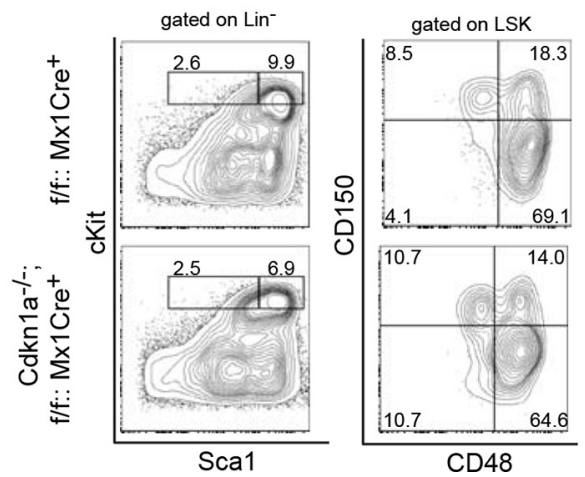

Figure 7. Interaction of $\mathrm{Cdkn} 1 a^{\text {cip } 1}$ but not $p 27^{\mathrm{kip} 1}$ with the Cul4-DDB1 complex (a) 293T cells were transiently co-transfected with plasmids expressing Myc-tagged Cul4a and Cdkn1 $a^{\text {cip1 }}$. Forty-eight hours post transfection, cells were harvested and lysed. Protein lysates were immunoprecipitated with anti-Myc antibody, and Western blotted for Cdkn1 $a^{\text {cip } 1}$ and DDB1. (b) Similarly as described in (a), p27 ${ }^{k i p} 1$ was tested for co-immunoprecipitation with the Cul4a-DDB1 complex. (c) Representative FACS analysis of bone marrows after polyl:C injection. Age matched littermates on a mixed 129xC57BL/6 background were used from 2 independent experiments ( $n=3-4$ per group).

\section{DDB1 interacts with distinct DCAF proteins in a cell type specific manner}

The different roles of DDB1 in distinct cell types suggested that cellular contexts are important for DDB1 function. One possibility is that the CUL4-DDB1 complex utilizes distinct DCAFs in different cells. To this end, we sought to identify DDB1-interacting proteins. We identified interacting proteins in three distinct cell types. The different cell types expressed DDB1 protein at similar levels (Figure 9a). First, DDB1-interacting proteins were identified in ESC by targeting DDB1 in tandem with Strepll/Flag tags in the Col1A locus and generating a doxycycline-inducible ESC cell line (Figure $9 b, d$ ). We also transiently expressed DDB1 in tandem with HA/Flag tags in 293T cells, and stably transduced DDB1 in tandem with Strep/Flag tags in a promyelocytic leukemia cell line capable of hematopoietic differentiation (HL60) (Figure 9c). Interacting proteins were identified using liquid chromatography-tandem mass spectrometry (LC-MS/MS). We identified 140 proteins in ESC, 110 proteins in 293T, and 128 in HL60 cells (Supplementary file 1). Interestingly very little overlap was found between subsets except CUL4A and proteins that make up the $26 \mathrm{~S}$ proteasome. Another subset of proteins identified in ESC and 293T analyses were known proteins found in CUL4 ${ }^{\mathrm{DDB} 1}$ complexes (CUL4B, CUL4B, VprBP, DDA1) (Figure 10a,b). Interaction of VprBP and DDB1 was validated in 293 T cells (Figure 10d). One subset of proteins that was of importance was the DCAF proteins since they are the substrate recognizing proteins in the CUL4 ${ }^{\mathrm{DDB} 1}$ complex (Lee and Zhou, 2007). In ESC we identified DCAF11, DCAF15, DCAF4, DCAF8, whereas in the hematopoietic cell line HL60 


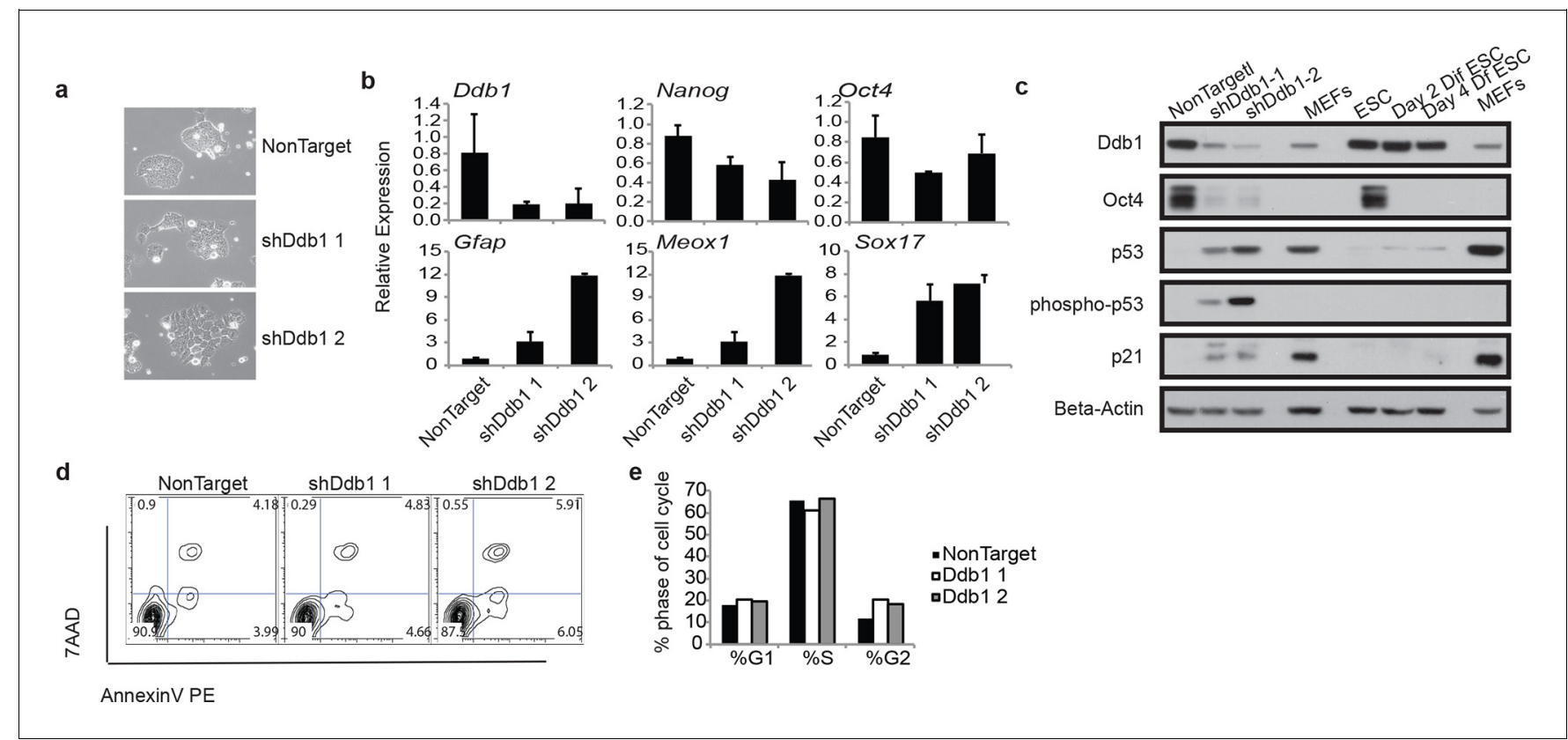

Figure 8. ESC loss of self-renewal after silencing of Ddb1 (a) Bright field picture of ESC colony 4 day post retroviral transfection. (b) Relative expression of pluripotency genes Oct4, and Nanog and genes representing endoderm (Sox17), mesoderm (Meox1) and ectoderm (GFAP) by qRT-PCR 4 days post selection. (c) Western blot of ESC 4 day post infection or differentiated in the presence of retinoic acid for up to 4 days. (d) Representative FACS blot of Annexin $V$ positive cells. $(n=3)$ n.s.: $p>0.05$. (e) Representative of cell cycle analysis. $(n=3)$ n.s.: $p>0.05$.

only DCAF7 was identified suggesting that differing complexes between cell types maybe responsible for the loss of DDB1 phenotype in different cell types (Figure 7a,c). To determine the DCAF proteins that responsible for the ESC DDB1-loss phenotype, we performed an RNAi screen targeting 15 known protein-members of the Cul4 ${ }^{\mathrm{DDB} 1}$ complex in ESC. Utilizing a reporter Nanog-GFP cell line as a marker of pluripotency we identified that of the DDB1-interacting DCAF proteins found in ESC silencing of DBA1, VprBP, and DCAF11 led to ESC differentiation (Figure 10e). Furthermore, depletion of DDA1, VprBP, and DCAF11 led to down-regulation of transcripts associated with ESC

a

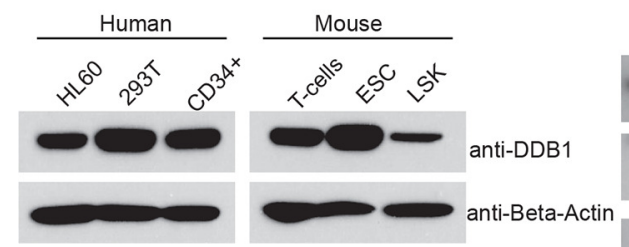

b

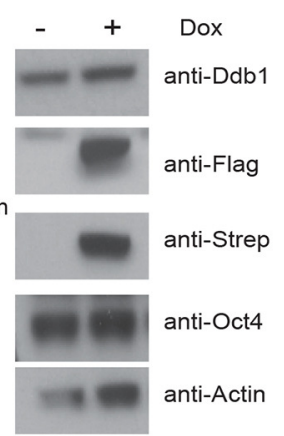

C

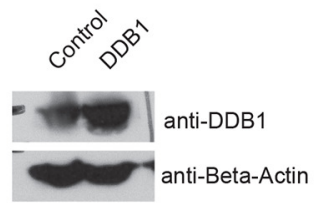

d

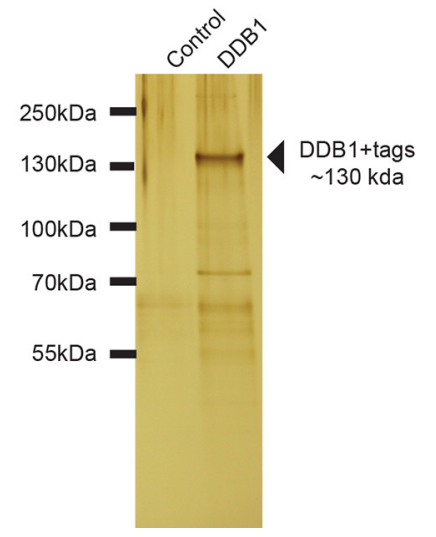

Figure 9. Tagged expression of DDB1 in ESC. (a) Western blot of DDB1 in different cell types. (b-c) Western blot of total protein and immunoprecipitated of tagged-DDB1 following Doxycycline induction in ESC (b) and HL-60 (c). (d) Silver staining of eluted tagged protein used for one mass spectrometry experiment in ESC.

DOI: 10.7554/eLife.07539.011 


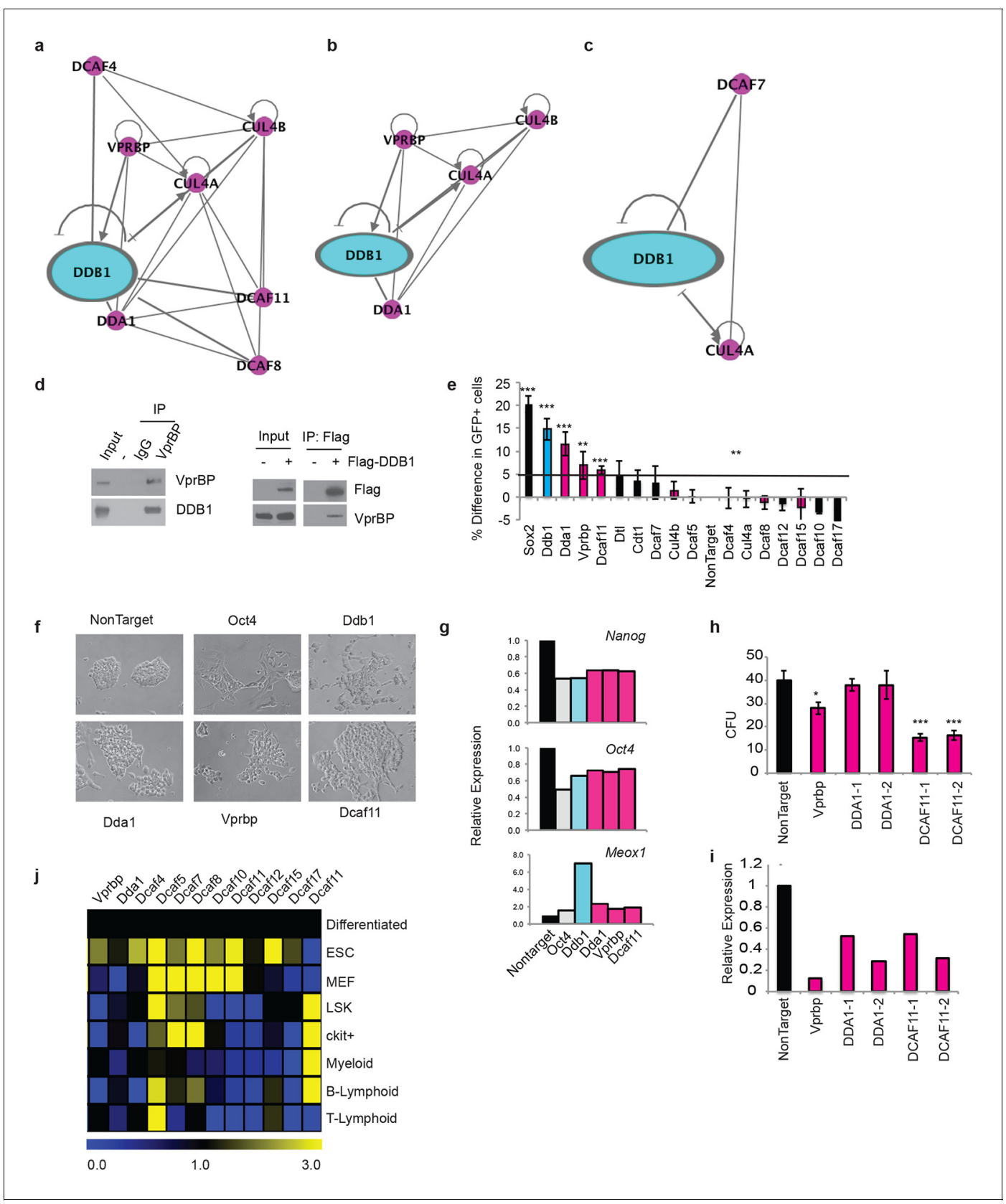

Figure 10. DDB1 interacts with VprBP and DCAF11 in ESC and are required for ESC self-renewal. (a-c) Ingenuity generated network of protein interactions of CUL4-DDB1 complex in (a) ESC, (b) 293T, and (c) HL-60. pink; DDB1 associated proteins (d) (left) immunprecipitation in 293T of endogenous VprBP protein followed by blotting for DDB1. (right) Transfection of Flag-DDB1 in 293T followed by immunopercipitation. (e-g) NanogGFP ES cells were transfected with pools of siRNAs under conditions of self-renewal and analyzed by FACS 72 hrs post-transfcetion. (e) Nanog-GFP expression. ( $n=3$ ) (pink= proteins identified in ESC mass spectrometry analysis; blue=DDB1) ( $f$ ) Bright field images of ESC colonies. (g) Representative experiment of relative expression of Nanog, Oct4, and Meox1. (n=3) (h) colony-forming units of LSK transduced with shRNAs. (i) Representative experiment of relative expression of following shRNA silencing. (j) Quantitative PCR of DCAFs in ESC and hematopoietic populations. (Differentiated= ESC differentiated for 48 hrs with retinoic acid). ${ }^{\star} p<0.05 .{ }^{* \star} p<0.01 .{ }^{\star \star \star} p<0.001$. DOI: 10.7554/eLife.07539.012

pluripotency (Figure 10g) and lead to morphology changes consistent with differentiation (Figure 10f). To determine if silencing of these DCAFs (DDA1, VprBP or DCAF11) in HSPC is also able to affect differentiation and/or maintenance, we transduced bone marrow-purified HSPC (LSK) cells with retroviruses expressing shRNAs against the selected DCAF genes. Interestingly, DDA1 silencing had no effect on colony formation in methylcellulose cultures, whereas a mild reduction in 
colonies was seen when VprBP was silenced. On the other hand, silencing of DCAF11 lead to a significant (greater than $50 \%$ ) reduction in colony formation (Figure 10h). shRNA silencing was confirmed to be greater than 60\% with all shRNAs (Figure 10i). These findings are consistent with the levels of DCAF11 expression in both LSK and Lineage ${ }^{\text {neg }} \mathrm{C}_{\mathrm{K}} \mathrm{Kit}^{+}$HSPC (Figure 10j). These findings suggest that different phenotypes in ESC, HSPC, and T-lymphocytes could be attributed to distinct substrate recognition by DDB1-associated DCAFs.

\section{Discussion}

In this study we identify Ddb1 as a critical regulator of stem cell homeostasis both in embryonic pluripotent and hematopoietic stem cells. Conditional ablation of Ddb1 in adult and fetal HSPCs, using the $\mathrm{Mx} 1 \mathrm{Cre}$ and Vav1Cre strains respectively, led to a complete loss of progenitors and stem cells, cytopenia, and acute lethality. Furthermore, increased levels of apoptosis and DNA damages were associated with acute Ddb1 inactivation in HSPCs, suggesting that Ddb1 regulates a wide range of cellular functions essential for the maintenance of hematopoiesis. Strikingly, inactivation of Ddb1 in resting lymphocytes (using the CD4Cre strain) had no significant effects. Whereas, silencing DDB1 in embryonic stem cells leads to loss of pluripotency and self-renewal devoid of alterations in cell cycle or cell survival. These observations demonstrate that Ddb1 is essential for stem cell self-renewal and differentiation in both HSPC and ESC. Previous studies demonstrate that the mechanism of CUL4DDB1 differs depending on the cell type (Bondar et al., 2006; Cang et al., 2006; Tardat et al., 2010; Kronke et al., 2014). Our studies suggest that Ddb1 deletion affects hematopoietic progenitors by triggering DNA damage and Trp53 response, leading to the rapid induction of apoptosis. Knockdown of DDB1 in ESC by shRNA is not as efficient as Cre- mediated genetic deletion. However, the DDB1 knockdown clearly is sufficient to affect ES cell pluripotency and lead to differentiation (with no effects on apoptosis). At the same time, when DDB1 was silenced (by the same shRNAs) in 293T cells these cells underwent rapid apoptosis, even if the knockdown was not $100 \%$ (data not shown). Similarly, silencing of DDB1 in Lineage ${ }^{\text {neg }} \mathrm{C}-\mathrm{Kit}^{+}$progenitors also lead to cell death and absence of colony formation in CFU assays (data not shown). Additionally, deleting DDB1 in the early embryo is lethal, however the embryos survive till around E12.5 far past the point of the proliferation of the inner cell mass, suggesting proliferation and differentiation during early embryogenesis could be DDB1-independent (Cang et al., 2006).

Ddb1 shows an intriguing pattern of expression during hematopoiesis. It is one of the highest expressed genes in the multipotent progenitor (MPP) fraction, and is induced as the quiescent HSCs differentiate. It is expressed in all progenitor populations with the highest levels in progenitors of $T$ cells. Several substrates of CUL4-DDB1 complex have been reported. Interestingly, it appears that there is tissue specificity for the various CUL4-DDB1 substrates. CDT1 and p27 $7^{\mathrm{Kip} 1}$ appear to be targeted by the complex in both brain and fibroblasts (Bondar et al., 2006; Cang et alo, 2006). c-JUN and Cdkn1 $a^{\text {cip } 1}$ are degraded by the CUL4-DDB1 complex in skin cells (Cang et al., 2007). More recently, PR-set7, a methyltransferase regulating replication origins, was found to be also a substrate for the CUL4-DDB1 ligase (Tardat et al., 2010). Ddb1 deletion resulted in accumulation of the Cdkn1a ${ }^{\text {cip1 }}$, a CDK and cell cycle inhibitor, protein in bone marrow progenitor populations and $T$ lymphocytes. On the other hand, we failed to demonstrate p2 $7^{\mathrm{kip} 1}$ stabilization in Ddb1-deleted hematopoietic cells (data not shown). Moreover, there was no detectable interaction between p2 $7^{\text {kip } 1}$ and the CUL4-DDB1 complex. In addition, we failed to detect in Ddb1-deleted progenitor cells accumulation of CDT1, a licensing factor of DNA replication (Hu et alo, 2004), or PR-set7 (Tardat et al., 2010). However, co-silencing Cdkn1a with Ddb1 did not rescue HSPC homeostasis, which suggests it is unlikely that DDB1 exerts its function solely by regulating $\mathrm{Cdkn} 1 \mathrm{a}^{\text {cip } 1}$ turnover in HSPC. Indeed DNA damage and acute induction of cell death were observed upon Ddb1 deletion. Trp53 pathway silencing partially restored HSPC cell number in Ddb1-deleted animals. It is likely that DDB1 controls a broader spectrum of cellular functions, through its interaction with additional novel protein substrates and the proteasome itself (data not shown). However, it should be noted that mice with mixed background were used for Trp53 and Cdkn1a rescue experiments. The phenotype could be strain-dependent due to variation in MHC alleles. More conclusive results would require crossing mice into pure background.

There are findings suggesting that DDB1 can exert its function independent of CUL4A/B (Lv et alı, 2010). However, DDB1 mainly functions as an adapter protein for the CUL4-DDB1 
complex. The specificity of the complex comes from the DCAF family of proteins that recognize specific substrates. Expression of DCAF proteins is cell-type specific and as we have shown pluripotent and adult stem cell populations vary in expression. Mass spectrometry analysis of DDB1 interacting proteins in ESC, 293T, and HL60 cell lines demonstrate differential binding to specific DCAF proteins suggesting different substrates in these different cellular contents that may correlate with the different phenotypes. Some of the previous identified substrates have been associated with cell cycle control and DNA damage, however Kronke et al. demonstrates that two lymphoid transcription factors (IKZF1 and IKZF3) are also targeted for degradation by CUL4-DDB1 complexes utilizing CRBN, a member of the DCAF family, as the substrate recognizing protein of the complex (Kronke et al., 2014). Although in our mass spectrometry analysis we did not identify CRBN as an interacting partner, we found in hematopoietic (primitive myeloid) cells that DCAF7 interacted with the CUL4-DDB1 complex whereas Vprbp and DCAF11 were found to interact with DDB1 and silencing in ESC mimicked the loss of DDB1 phenotype. Interestingly, in multiple myeloma cells treatment with lenalidomide increased ubiquitination and subsequent degradation of IKZF1 and IKZF3, demonstrating that small molecules can modulate the CUL4-DDB1-DCAF complex.

\section{Materials and methods}

\section{Animals}

$D d b 1^{f / f}$ mice and their genotyping were previously reported (Long et al., 2001; Zhang et al., 2001). Ddb1f/f::Mx1Cre ${ }^{+}$animals were on C57BL/6 background, and were injected with $10 \mu \mathrm{g}$ polyl:C per gram of body weight every two days for total two or three injections and analyzed 3 days from last injection depending on the experiments. For mice transplanted with Ddb1f/f::Mx1Cre ${ }^{+}$bone marrow, host mice got three polyl:C injections every two days. $D d b 1^{f / f} C D 4 C r e^{+}$mice were analyzed at 4-6 weeks of age. Trp53 ${ }^{-/-}$and Cdkn1 $\mathrm{a}^{\text {cip-/- }}$ were purchased from Jackson Laboratory and on a mixed 129xC57BL/6 background, and crossed with $\mathrm{Ddb} 1^{\mathrm{f} / \mathrm{f}}:: \mathrm{MxCre}{ }^{+}$to obtain $\operatorname{Trp} 53^{-/-}:: \mathrm{Ddb} 1^{\mathrm{f} / \mathrm{f}}::$

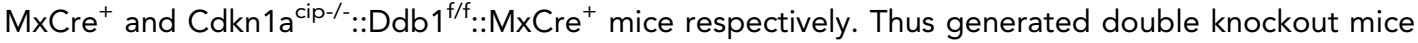
and littermates were on a mixed $129 \times \mathrm{C} 57 \mathrm{BL} / 6$ background). All animal experiments were done in accordance to the guidelines of the NYU School of Medicine. The breeding schemes for $\operatorname{Trp} 53^{-/-}::$ $\mathrm{Ddb} 1^{\mathrm{f} / \mathrm{f}}:: \mathrm{MxCre}{ }^{+}$double knockout mice were as follows:

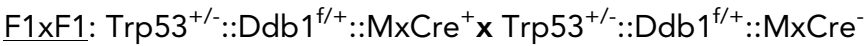

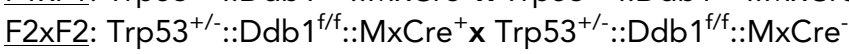

F3: $\operatorname{Trp} 53^{-/-}:: \mathrm{Ddb} 1^{\mathrm{f} / \mathrm{f}}:: \mathrm{MxCre}{ }^{+}$, or $\operatorname{Trp} 53^{+/+}:: \mathrm{Ddb} 1^{\mathrm{f} / \mathrm{f}}:: \mathrm{MxCr \textrm {C } ^ { + }}$

Littermates were selected for experiments. The breeding schemes for obtaining $\mathrm{Cdkn} 1 \mathrm{a}^{-/-}: \mathrm{Ddb} 1^{\mathrm{f} /}$

$f_{:: M x C r e}{ }^{+}$double knockout mice were similar as above.

\section{Antibodies and FACS analysis}

Antibody staining and FACS analysis was performed as previously described (Aifantis et al., 1999). All antibodies were purchased from BD-Pharmingen or e-Bioscience. We used the following antibodies: c-kit (2B8), Sca-1 (D7), Mac-1 (M1/70), Gr-1 (RB6-8C5), NK1.1 (PK136), TER-119, CD3 (1452C11), CD19 (1D3), CD4 (RM4-5), CD4 (H129.19), CD8 (53-6.7), CD25 (PC61), CD44 (IM7), CD45.1 (A20), CD45.2 (104), CD150 (9D1), CD48 (HM481), AnnexinV, 7-AAD. Bone marrow lineage antibody cocktail includes: Mac-1, Gr-1, NK1.1, TER-119, CD3, CD19. For DAPI staining, briefly, the cells were first treated with Fix and Perm reagents according to manufacturer's instruction (Invitrogen), then resuspended in PBS with $5 \mu \mathrm{g} / \mathrm{ml}$ RNaseA and $2 \mu \mathrm{g} / \mathrm{ml}$ DAPI. $\gamma \mathrm{H} 2 \mathrm{Ax}$ staining, TUNEL analysis (Millipore) and BrdU staining (BD Pharmingen) were performed according to manufacturer's instruction respectively. The following antibodies were used for Western blot analysis: Ddb1 (Invitrogen), Cdkn1a (C-19) (Santa Cruz) and phospho-Trp53 (Ser15) (Cell signaling) and $\beta$-actin (Millipore). DCAF1 antibody was previously described (McCall et al.,, 2008).

\section{RT-PCR}

Total RNA was isolated using the RNeasy Plus Mini Kit (Qiagen) and cDNA was synthesized using the SuperScript First-Strand Kit (Invitrogen). Quantitative PCR was performed using iQ SYBR Green Supermix and an iCycler (Bio-Rad) using the primer sequences $\left(\mathrm{Tm}=60^{\circ} \mathrm{C}\right.$ used for all primers). 


\section{Methylcellulose assay and bone marrow transplantation}

Total bone marrow from polyl:C injected Ddb1f/f::Mx1Cre ${ }^{+}$or control mice were plated in duplicate $(200,000$ cells $/ 35 \mathrm{~mm}$ dish) into cytokine-supplemented methylcellulose medium (MethoCult 3434 , Stem Cell Technologies), and the number and morphology of colonies were scored 7 days later. Alternatively, lineage negative bone marrow cells were isolated by using EasySep Kit (StemCell Technology), and infected with retrovirus expressing pMig-IRES-GFP or pMig-Cre-GFP (see below). Similarly for shRNA infection, Ckit+ enriched bone marrow cells (Automacs technology) where transduced with pLMP-Renilla, pLMP-VprBP, pLMP-DCAF11 or pLMP-DDA1). Forty-eight hours post infection, Lineage $\mathrm{GFP}^{+}$cells were sorted and 4,000 cells were plated in methylcellulose. For CFU-S assay, 100,000 bone marrow cells were injected into lethally irradiated ( 960 cGy) host mice ( $n=5$ per group). Spleens were taken at day 8 and fixed in Bouin's solution overnight and colonies were counted. For bone marrow transplantation, $2 \times 10^{5}$ bone marrow cells were transplanted by retroorbital i.v. injections into lethally irradiated (960 cGy) BL6SJL recipient mice.

\section{Microarray and gene set enrichment analysis}

Duplicate of each sample was used. Three mice were pooled from each genotype for the DN3 microarray experiment. Microarray analysis was performed as previously described (Gao et al., 2009). Briefly, freshly isolated cells were sorted by surface marker expression, and total RNA was extracted using the RNeasy kit (QIAGEN, CA). In order to generate sufficient sample quantities for oligonucleotide gene chip hybridization experiments, we used the GeneChip Two-Cycle cDNA Synthesis Kit (Affymetrix, San Jose, CA) for cRNA amplification and labeling. The amplified cRNA was labeled and hybridized to the MOE430 Plus 2 oligonucleotide arrays (Affymetrix). The Affymetrix gene expression profiling data was normalized using the previously published Robust Multi-array Average (RMA) algorithm using the GeneSpring 7 software (Agilent, Palo Alto, CA). The gene expression intensity presentation was generated with $\mathrm{MeV}$ software (http://www.tm4.org). Microarray data were deposited under the GEO database with the accession number (GSE70658). Gene set enrichment analysis was performed using Gene Set Enrichment Analysis software (Mootha et al., 2003; Subramanian et al., 2007) (http://www.broadinstitute.org/gsea) using gene set as permutation type, 1,000 permutations and log2 ratio of classes as metric for ranking genes. The 'stem' and 'diff' gene set was from publication ( $\mathrm{Ng}$ et al., 2009). Other gene sets used in the analysis were taken from gene sets already present in the MSig database of the Broad Institute.

\section{ESC culture and siRNA}

ESC were cultured and transfected with siRNA as previously described (Buckley et al., 2012). Human DDB1 cDNA in tandem with Strepll/Flag tags were cloned into pBS31 cloning vector (Hochedlinger et al., 2005; Beard et al., 2006). Plasmid (pBS31-N-SF-DDB1) was then nucleoporatated (Amaxa) along with FlpE plasmid into KH2 ESC. ESCs were selected with hygromycin for 10 days. Expression of tagged protein was confirmed by western blot following treatment with doxyclyine for 3 days.

\section{Mass spectrometry of purified tagged proteins}

293T cells were transfected with pCDNA-HA-Flag-DDB1 or pCDNA-HA-Flag. $48 \mathrm{hr}$ post transfection cells were treated with $10 \mu \mathrm{M}$ MG132 for 4 hrs prior to collection of cells. HL-60 were transduced with pMIG-N-SF-DDB1 and selected with puromycin for 5 days $48 \mathrm{hrs}$ following transduction. pBS31-N-SF-DDB1 or pBS31-N-SF targeted ESCs were induced with $2 \mu \mathrm{M}$ doxycycline (Sigma) for 3

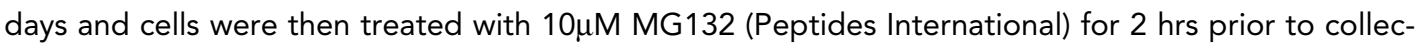
tion of the cells. Cell pellets were resuspended in Lysis Buffer $(100 \mathrm{mM}$ Tris- $\mathrm{HCl}$ pH7.5, $150 \mathrm{mM}$ $\mathrm{NaCl}, 1 \%$ Triton-X100, $1 \mathrm{mM}$ EDTA, $2 \mathrm{mM} \mathrm{MgCl}$, and supplemented with Complete Mini protease inhibitors (Roche), and $10 \mathrm{mM} \mathrm{N}$-elthylmaleimide (Sigma). Tagged proteins were bound to StrepTactin macroprep beads (IBA), and eluted per manufactuers instructions. Peptides were digested with trypsin and analyzed by LC-MS/MS. The MS/MS spectra were searched against NCBI database using a local MASCOT search engine (V.2.3). 


\section{Statistical analysis}

The means of each data set were analyzed using the Student's $t$ test, with a two-tailed distribution and assuming equal sample variance.

\section{Acknowledgements}

We would like to thank the NYU Genome Technology Center (supported in part by NIH/NCI P30 CA016087-30 grant) for expert assistance with micro-array experiments, and the NYU Flow Cytometry facility (supported in part by NIH/NCI 5 P30CA16087-31) for expert cell sorting, the NYU Histology Core (5P30CA16087-31), and the Transgenic Mouse Core (NYU Cancer Institute Center Grant (5P30CA16087-31). We would also like to thank Dr H Li and Dr T Liu at the Center for Advanced Proteomics Research, Rutgers New Jersey School of Medicine, and Dr B Ueberheide at the NYU School of Medicine Proteomics Resource Center supported by the Cancer Center Support Grant, P30CA016087 for selected mass spectrometry analysis. IA is supported by the National Institutes of Health (RO1CA133379, RO1CA105129, R21CA141399, RO1CA149655, and RO1GM088847), NYS Department of Health NY STEM (C028130), the Leukemia \& Lymphoma Society (TRP grant), the V Foundation for Cancer Research, the Irma T. Hirschl Trust, and the Dana Foundation. JG was supported by the Lady Tata Memorial Trust and Molecular Oncology and Immunology training grant, and SMB was supported by the Helen L and Martin S Kimmel Stem Cell Postdoctoral fellowship and the NIH institutional training grant (1T32CA160002-01).

\section{Additional information}

Competing interests

SPG: Reviewing editor, eLife. The other authors declare that no competing interests exist.

Funding

\begin{tabular}{ll} 
Funder & Author \\
\hline National Cancer Institute & lannis Aifantis \\
\hline $\begin{array}{l}\text { The funders had no role in study design, data collection and interpretation, or the } \\
\text { decision to submit the work for publication. }\end{array}$
\end{tabular}

Author contributions

JG, SMB, Conception and design, Acquisition of data, Analysis and interpretation of data, Drafting or revising the article; LC, MG, AS, Conception and design, Acquisition of data, Analysis and interpretation of data; YC, Acquisition of data, Analysis and interpretation of data, Contributed unpublished essential data or reagents; SPG, Conception and design, Acquisition of data, Contributed unpublished essential data or reagents; IA, Conception and design, Analysis and interpretation of data, Drafting or revising the article

Ethics

Animal experimentation: All animal experiments were done in accordance to the guidelines of the NYU School of Medicine, and approved by the institutional animal care and use committee (IACUC) protocol (\#130410-03).

\section{Additional files}

Supplementary files

- Supplementary file 1. DDB1 interacting proteins in ESC, 293T, and HL60 cells. Mass spectrometry results for DDB1 interacting proteins in 3 different cell types, ESC, 293T, and HL60. Columns A) accession number either swiss-prot or ncbi; B) protein molecular weight; C) Gene Symbol; D) Gene name; E) \# of peptides in control; and F) \# of proteins in DDB1.

DOI: 10.7554/eLife.07539.013 
Major datasets

The following datasets were generated:

\begin{tabular}{|c|c|c|c|c|}
\hline Author(s) & Year & Dataset title & $\begin{array}{l}\text { Dataset ID } \\
\text { and/or URL }\end{array}$ & $\begin{array}{l}\text { Database, license, } \\
\text { and accessibility in- } \\
\text { formation }\end{array}$ \\
\hline $\begin{array}{l}\text { Gao J, Buckley S, } \\
\text { Song G, Mullighan } \\
\text { CG, Cang Y, Goff } \\
\text { SP, Aifantis I }\end{array}$ & 2015 & $\begin{array}{l}\text { The E3 ubiquitin ligase DDB1 con- } \\
\text { trols homeostasis of hematopoietic } \\
\text { stem and progenitor cells }\end{array}$ & $\begin{array}{l}\text { http://www.ncbi.nlm.nih. } \\
\text { gov/geo/query/acc.cgi? } \\
\text { acc=GSE70658 }\end{array}$ & $\begin{array}{l}\text { Publicly available at } \\
\text { the NCBI Gene } \\
\text { Expression Omnibus } \\
\text { (Accession no: } \\
\text { GSE70658). }\end{array}$ \\
\hline
\end{tabular}

\section{References}

Abbas T, Sivaprasad U, Terai K, Amador V, Pagano M, Dutta A. 2008. PCNA-dependent regulation of p21 ubiquitylation and degradation via the CRL4Cdt2 ubiquitin ligase complex. Genes \& Development 22:24962506. doi: $10.1101 / \mathrm{gad} .1676108$

Aifantis I, Feinberg J, Fehling HJ, Di Santo JP, von Boehmer H. 1999. Early t cell receptor gene expression is regulated by the pre-t cell receptor-CD3 complex. Journal of Experimental Medicine 190:141-144. doi: 10. 1084/jem.190.1.141

Angers S, Li T, Yi X, MacCoss MJ, Moon RT, Zheng N. 2006. Molecular architecture and assembly of the DDB1CUL4A ubiquitin ligase machinery. Nature 443:590-593. doi: 10.1038/nature05175

Batty D, Rapic'-Otrin V, Levine AS, Wood RD. 2000. Stable binding of human XPC complex to irradiated DNA confers strong discrimination for damaged sites. Journal of Molecular Biology 300:275-290. doi: 10.1006/jmbi. 2000.3857

Beard C, Hochedlinger K, Plath K, Wutz A, Jaenisch R. 2006. Efficient method to generate single-copy transgenic mice by site-specific integration in embryonic stem cells. Genesis 44:23-28. doi: 10.1002/gene.20180

Bondar T, Kalinina A, Khair L, Kopanja D, Nag A, Bagchi S, Raychaudhuri P. 2006. Cul4A and DDB1 associate with Skp2 to target p27Kip1 for proteolysis involving the COP9 signalosome. Molecular and Cellular Biology 26:2531-2539. doi: 10.1128/MCB.26.7.2531-2539.2006

Braun S, Garcia JF, Rowley M, Rougemaille M, Shankar S, Madhani HD. 2011. The Cul4-Ddb1Cdt2 ubiquitin ligase inhibits invasion of a boundary-associated antisilencing factor into heterochromatin. Cell 144:41-54. doi: 10.1016/j.cell.2010.11.051

Buckley SM, Aranda-Orgilles B, Strikoudis A, Apostolou E, Loizou E, Moran-Crusio K, Farnsworth CL, Koller AA, Dasgupta R, Silva JC, Stadtfeld M, Hochedlinger K, Chen El, Aifantis I. 2012. Regulation of pluripotency and cellular reprogramming by the ubiquitin-proteasome system. Cell Stem Cell 11:783-798. doi: 10.1016/j.stem. 2012.09.011

Cang Y, Zhang J, Nicholas SA, Bastien J, Li B, Zhou P, Goff SP. 2006. Deletion of DDB1 in mouse brain and lens leads to p53-dependent elimination of proliferating cells. Cell 127:929-940. doi: 10.1016/j.cell.2006.09.045

Cang Y, Zhang J, Nicholas SA, Kim AL, Zhou P, Goff SP. 2007. DDB1 is essential for genomic stability in developing epidermis. Proceedings of the National Academy of Sciences of the United States of America 104: 2733-2737. doi: 10.1073/pnas.0611311104

Cheng T. 2000. Hematopoietic stem cell quiescence maintained by p21cip1/waf1. Science 287:1804-1808. doi: 10.1126/science.287.5459.1804

Crusio KM, King B, Reavie LB, Aifantis I. 2010. The ubiquitous nature of cancer: the role of the SCFFbw7 complex in development and transformation. Oncogene 29:4865-4873. doi: 10.1038/onc.2010.222

D'Arca D, Zhao X, Xu W, Ramirez-Martinez NC, lavarone A, Lasorella A. 2010. Huwe1 ubiquitin ligase is essential to synchronize neuronal and glial differentiation in the developing cerebellum. Proceedings of the National Academy of Sciences of the United States of America 107:5875-5880. doi: 10.1073/pnas.0912874107

de Sauvage FJ. 1996. Physiological regulation of early and late stages of megakaryocytopoiesis by thrombopoietin. Journal of Experimental Medicine 183:651-656. doi: 10.1084/jem.183.2.651

Fischer ES, Böhm K, Lydeard JR, Yang H, Stadler MB, Cavadini S, Nagel J, Serluca F, Acker V, Lingaraju GM, Tichkule RB, Schebesta M, Forrester WC, Schirle M, Hassiepen U, Ottl J, Hild M, Beckwith REJ, Harper JW, Jenkins JL, Thomä NH. 2014. Structure of the DDB1-CRBN E3 ubiquitin ligase in complex with thalidomide. Nature 512:49-53. doi: 10.1038/nature13527

Gao J, Graves S, Koch U, Liu S, Jankovic V, Buonamici S, El Andaloussi A, Nimer SD, Kee BL, Taichman R, Radtke F, Aifantis I. 2009. Hedgehog signaling is dispensable for adult hematopoietic stem cell function. Cell Stem Cell 4:548-558. doi: 10.1016/j.stem.2009.03.015

He YJ, McCall CM, Hu J, Zeng Y, Xiong Y. 2006. DDB1 functions as a linker to recruit receptor WD40 proteins to CUL4-ROC1 ubiquitin ligases. Genes \& Development 20:2949-2954. doi: 10.1101/gad.1483206

Higa LA, Wu M, Ye T, Kobayashi R, Sun H, Zhang H. 2006. CUL4-DDB1 ubiquitin ligase interacts with multiple WD40-repeat proteins and regulates histone methylation. Nature Cell Biology 8:1277-1283. doi: 10.1038/ ncb1490

Higa LAA, Mihaylov IS, Banks DP, Zheng J, Zhang H. 2003. Radiation-mediated proteolysis of CDT1 by CUL4ROC1 and CSN complexes constitutes a new checkpoint. Nature Cell Biology 5:1008-1015. doi: 10.1038/ ncb1061 
Hochedlinger K, Yamada Y, Beard C, Jaenisch R. 2005. Ectopic expression of oct-4 blocks progenitor-cell differentiation and causes dysplasia in epithelial tissues. Cell 121:465-477. doi: 10.1016/j.cell.2005.02.018

Hu J, McCall CM, Ohta T, Xiong Y. 2004. Targeted ubiquitination of CDT1 by the DDB1-CUL4A-ROC1 ligase in response to DNA damage. Nature Cell Biology 6:1003-1009. doi: 10.1038/ncb1172

Kronke J, Udeshi ND, Narla A, Grauman P, Hurst SN, McConkey M, Svinkina T, Heckl D, Comer E, Li X, Ciarlo C, Hartman E, Munshi N, Schenone M, Schreiber SL, Carr SA, Ebert BL. 2014. Lenalidomide causes selective degradation of IKZF1 and IKZF3 in multiple myeloma cells. Science 343:301-305. doi: 10.1126/science.1244851

Kuhn R, Schwenk F, Aguet M, Rajewsky K. 1995. Inducible gene targeting in mice. Science 269:1427-1429. doi: 10.1126/science.7660125

Lee J, Zhou P. 2007. DCAFs, the missing link of the CUL4-DDB1 ubiquitin ligase. Molecular Cell 26:775-780. doi: 10.1016/j.molcel.2007.06.001

Liu L, Lee S, Zhang J, Peters SB, Hannah J, Zhang Y, Yin Y, Koff A, Ma L, Zhou P. 2009. CUL4A abrogation augments DNA damage response and protection against skin carcinogenesis. Molecular Cell 34:451-460. doi: 10.1016/j.molcel.2009.04.020

Long F, Zhang XM, Karp S, Yang Y, McMahon AP. 2001. Genetic manipulation of hedgehog signaling in the endochondral skeleton reveals a direct role in the regulation of chondrocyte proliferation. Development 128 : 5099-5108.

Lv X-B, Xie F, Hu K, Wu Y, Cao L-L, Han X, Sang Y, Zeng Y-X, Kang T. 2010. Damaged DNA binding protein 1 (dDB1) interacts with ${ }^{\mathrm{Cdh} 1}$ and modulates the function of APC/C ${ }^{\text {Cdh1 }}$. Journal of Biological Chemistry 285:jbc. M109.094144-18240. doi: 10.1074/jbc.M109.094144

Matsuoka S, Oike Y, Onoyama I, Iwama A, Arai F, Takubo K, Mashimo Y, Oguro H, Nitta E, Ito K, Miyamoto K, Yoshiwara H, Hosokawa K, Nakamura Y, Gomei Y, Iwasaki H, Hayashi Y, Matsuzaki Y, Nakayama K, Ikeda Y, Hata A, Chiba S, Nakayama KI, Suda T. 2008. Fbxw7 acts as a critical fail-safe against premature loss of hematopoietic stem cells and development of t-ALL. Genes \& Development 22:986-991. doi: 10.1101/gad. 1621808

McCall CM, Miliani de Marval PL, Chastain PD, Jackson SC, He YJ, Kotake Y, Cook JG, Xiong Y. 2008. Human immunodeficiency virus type 1 vpr-binding protein VprBP, a WD40 protein associated with the DDB1-CUL4 E3 ubiquitin ligase, is essential for DNA replication and embryonic development. Molecular and Cellular Biology 28:5621-5633. doi: 10.1128/MCB.00232-08

Mootha VK, Lindgren CM, Eriksson K-F, Subramanian A, Sihag S, Lehar J, Puigserver P, Carlsson E, Ridderstråle M, Laurila E, Houstis N, Daly MJ, Patterson N, Mesirov JP, Golub TR, Tamayo P, Spiegelman B, Lander ES, Hirschhorn JN, Altshuler D, Groop LC. 2003. PGC-1-responsive genes involved in oxidative phosphorylation are coordinately downregulated in human diabetess. Nature Genetics 34:267-273. doi: 10.1038/ng1180

Nakada D, Saunders TL, Morrison SJ. 2010. Lkb1 regulates cell cycle and energy metabolism in haematopoietic stem cells. Nature 468:653-658. doi: 10.1038/nature09571

Ng SY-M, Yoshida T, Zhang J, Georgopoulos K. 2009. Genome-wide lineage-specific transcriptional networks underscore ikaros-dependent lymphoid priming in hematopoietic stem cells. Immunity 30:493-507. doi: 10. 1016/j.immuni.2009.01.014

Nishitani H, Shiomi Y, lida H, Michishita M, Takami T, Tsurimoto T. 2008. CDK inhibitor p21 is degraded by a proliferating cell nuclear antigen-coupled Cul4-DDB1Cdt2 pathway during s phase and after UV irradiation. Journal of Biological Chemistry 283:29045-29052. doi: 10.1074/jbc.M806045200

Oda H, Hübner MR, Beck DB, Vermeulen M, Hurwitz J, Spector DL, Reinberg D. 2010. Regulation of the histone $\mathrm{H} 4$ monomethylase PR-Set7 by CRL4Cdt2-mediated PCNA-dependent degradation during DNA damage. Molecular Cell 40:364-376. doi: 10.1016/j.molcel.2010.10.011

Orkin SH, Zon LI. 2008. Hematopoiesis: an evolving paradigm for stem cell biology. Cell 132:631-644. doi: 10. 1016/j.cell.2008.01.025

Ramakrishna S, Suresh B, Lim K-H, Cha B-H, Lee S-H, Kim K-S, Baek K-H. 2011. PEST motif sequence regulating human NANOG for proteasomal degradation. Stem Cells and Development 20:1511-1519. doi: 10.1089/scd. 2010.0410

Rathinam C, Matesic LE, Flavell RA. 2011. The E3 ligase itch is a negative regulator of the homeostasis and function of hematopoietic stem cells. Nature Immunology 12:399-407. doi: 10.1038/ni.2021

Rathinam C, Thien CBF, Langdon WY, Gu H, Flavell RA. 2008. The E3 ubiquitin ligase c-cbl restricts development and functions of hematopoietic stem cells. Genes \& Development 22:992-997. doi: 10.1101/gad.1651408

Reavie L, Gatta GD, Crusio K, Aranda-Orgilles B, Buckley SM, Thompson B, Lee E, Gao J, Bredemeyer AL, Helmink BA, Zavadil J, Sleckman BP, Palomero T, Ferrando A, Aifantis I. 2010. Regulation of hematopoietic stem cell differentiation by a single ubiquitin ligase-substrate complex. Nature Immunology 11:207-215. doi: 10.1038/ni.1839

Stadtfeld M. 2005. Assessing the role of hematopoietic plasticity for endothelial and hepatocyte development by non-invasive lineage tracing. Development 132:203-213. doi: 10.1242/dev.01558

Stier S. 2002. Notch1 activation increases hematopoietic stem cell self-renewal in vivo and favors lymphoid over myeloid lineage outcome. Blood 99:2369-2378. doi: 10.1182/blood.V99.7.2369

Subramanian A, Kuehn H, Gould J, Tamayo P, Mesirov JP. 2007. GSEA-p: a desktop application for gene set enrichment analysis. Bioinformatics 23:3251-3253. doi: 10.1093/bioinformatics/btm369

Sugasawa K, Okuda Y, Saijo M, Nishi R, Matsuda N, Chu G, Mori T, Iwai S, Tanaka K, Tanaka K, Hanaoka F. 2005. UV-induced ubiquitylation of XPC protein mediated by UV-DDB-ubiquitin ligase complex. Cell 121:387400. doi: 10.1016/j.cell.2005.02.035 
Tardat M, Brustel J, Kirsh O, Lefevbre C, Callanan M, Sardet C, Julien E. 2010. The histone H4 lys 20 methyltransferase PR-Set7 regulates replication origins in mammalian cells. Nature Cell Biology 12:1086-1093. doi: 10.1038/ncb2113

Thompson BJ, Jankovic V, Gao J, Buonamici S, Vest A, Lee JM, Zavadil J, Nimer SD, Aifantis I. 2008. Control of hematopoietic stem cell quiescence by the E3 ubiquitin ligase Fbw7. Journal of Experimental Medicine 205: 1395-1408. doi: 10.1084/jem.20080277

Tothova Z, Kollipara R, Huntly BJ, Lee BH, Castrillon DH, Cullen DE, McDowell EP, Lazo-Kallanian S, Williams IR, Sears C, Armstrong SA, Passegué E, DePinho RA, Gilliland DG. 2007. FoxOs are critical mediators of hematopoietic stem cell resistance to physiologic oxidative stress. Cell 128:325-339. doi: 10.1016/j.cell.2007. 01.003

Wilson A. 2004. C-myc controls the balance between hematopoietic stem cell self-renewal and differentiation. Genes \& Development 18:2747-2763. doi: 10.1101/gad.313104

Xu H, Wang W, Li C, Yu H, Yang A, Wang B, Jin Y. 2009. WWP2 promotes degradation of transcription factor OCT4 in human embryonic stem cells. Cell Research 19:561-573. doi: 10.1038/cr.2009.31

Zhang J, Niu C, Ye L, Huang H, He X, Tong W-G, Ross J, Haug J, Johnson T, Feng JQ, Harris S, Wiedemann LM, Mishina Y, Li L. 2003. Identification of the haematopoietic stem cell niche and control of the niche size. Nature 425:836-841. doi: 10.1038/nature02041

Zhang XM, Ramalho-Santos M, McMahon AP. 2001. Smoothened mutants reveal redundant roles for shh and ihh signaling including regulation of L/R asymmetry by the mouse node. Cell 105:781-792. doi: 10.1016/S00928674(01)00385-3

Zsebo KM, Williams DA, Geissler EN, Broudy VC, Martin FH, Atkins HL, Hsu R-Y, Birkett NC, Okino KH, Murdock DC, Jacobsen FW, Langley KE, Smith KA, Takeish T, Cattanach BM, Galli SJ, Suggs SV. 1990. Stem cell factor is encoded at the SI locus of the mouse and is the ligand for the c-kit tyrosine kinase receptor. Cell 63:213-224. doi: 10.1016/0092-8674(90)90302-U 